\title{
Justicia digital post-covid19: el desafío de las soluciones extrajudiciales electrónicas de litigios y la inteligencia artificial
}

\author{
Post-covid19 digital justice: the challenge of ODR solutions and artificial intelligence
}

\author{
FERNANDO MARTÍN DIZ \\ Catedrático de Derecho Procesal \\ Universidad de Salamanca \\ fmdiz@usal.es \\ https://orcid.org/0000-0002-9288-8204
}

\begin{abstract}
Resumen: La pandemia causada por el virus COVID-19 ha tenido, y tendrá durante un tiempo, importantes repercusiones. El mundo de la justicia no será ajeno a estos cambios. La tecnología será el gran aliado estratégico en la evolución de una justicia menos presencial y más telemática. Es por ello que en el presente trabajo hemos estudiado, en primer lugar, la incidencia sobre el principio de inmediación, característico de las formas de obtener justicia. Un principio que evolucionará hacia una versión virtual. En segundo lugar, hemos analizado, puesto que consideramos que puede ser uno de los mayores avances en el ámbito de la Justicia post-covid19, la evolución que pueden presentar los medios extrajudiciales de resolución de litigios en línea y el desafío de incorporar a estas soluciones de inteligencia artificial.
\end{abstract}

Abstract: The pandemic caused by COVID-19 virus has had, and will have for some time, significant repercussions. The world of justice will not be oblivious to these changes. Technology will be the great strategic ally in the evolution of a less face-to-face and more telematic justice. That is the reason why, in the present work, we have studied, in the first place, the incidence on the principle of immediacy, characteristic of the ways of obtaining justice. A principle that will evolve into a virtual version. Secondly, we have analyzed, since we consider that it may be one of the greatest advances in the field

Cómo citar este trabajo: MARTÍN DIZ, Fernando, “Justicia digital post-covid19: el desafío de las soluciones extrajudiciales electrónicas de litigios y la inteligencia artificial", Revista de Estudios Jurídicos y Criminológicos, ISSN-e: 2660-7964, n. ${ }^{\circ}$ 2, Universidad de Cádiz, 2020, pp. 41-74, DOI: https://doi.org/10.25267/REJUCRIM.2020.i2.03 
of post-covid Justice19, the development that online out-of-court dispute resolution can present and the challenge of incorporating artificial intelligence into these solutions.

Palabras clave: Justicia, Tecnología, Principio de inmediación, Medios extrajudiciales de litigios en línea, inteligencia artificial

Key-words: Justice, Technology, Judicial immediacy, ODR, Artificial Intelligence.

SUMARIO: 1. JUSTICIA DIGITAL: UNA APROXIMACIÓN OMNICOMPRENSIVA 2. EL ENTORNO ACTUAL: UNA JUSTICIA POST-PANDEMIA. 3. ¿EL PRINCIPIO DE INMEDIACIÓN SE VIRTUALIZA? 3.1. El principio de inmediación: significado y alcance. 3.2. Transición hacia otra dimensión de la inmediación: la virtualización de las actuaciones procesales. 3.3. Elementos para la virtualización en el proceso desde el principio de inmediación. 4. ¿TECNOLÓGICAMENTE SON MÁS ÁGILES Y VENTAJOSAS LAS SOLUCIONES EXTRAJUDICIALES DE LITIGIOS? 5. MEDIOS EXTRAJUDICIALES DE RESOLUCIÓN DE LITIGIOS, TECNOLOGÍA E INTELIGENCIA ARTIFICIAL: EL RETO DEL PRESENTE. 5.1. ¿Qué es inteligencia artificial en el ámbito jurídico? 5.2. El desafío de incorporar la inteligencia artificial en el entorno de los ODR. 5.2.A. Inteligencia artificial con funciones asistenciales en entornos ODR. 5.2.B. Un modelo de transición en ODR con aplicaciones de inteligencia artificial. 5.2.C. Inteligencia artificial decisoria en ODR: ¿i-arbitraje o imediación? 6. VALORACIÓN CONCLUSIVA. 7. RELACIÓN BIBLIOGRÁFICA.

\section{JUSTICIA DIGITAL: UNA APROXIMACIÓN OMNICOMPRENSIVA}

La evolución de la Justicia del siglo XXI pasa inexorablemente por su digitalización. La Justicia, como elemento que integra la cultura, la sociedad, la convivencia, las relaciones sociales, humanas y profesionales, no puede ser ajena a la realidad para la que se aplica. Y la realidad de nuestro siglo es la de la denominada "cuarta revolución industrial"1, encarnada y sostenida sobre el uso y aprovechamiento de las nuevas tecnologías de la comunicación y de la información. La tarea, ya de partida, no es sencilla. Más en un ámbito tan específico como el Derecho, en general, y la Justicia, en particular, poco acostumbrado a la modernización, la dinamización y la innovación. Pero el momento ha llegado, la sociedad lo reclama y el derecho lo necesita, una justicia abierta y digital ${ }^{2}$ es imprescindible, y las reformas legales, ya sean estructurales o puntuales deben apostar por ello firmemente. Una inversión de poco más de 100 millones de euros anuales, según consta en los últimos ejercicios presupuestarios, para la

\footnotetext{
${ }^{1}$ SCHWAB, K., La cuarta revolución industrial, Ed. Debate, 2016.

${ }^{2}$ CORTÉS ABAD, O., "Justicia digital, abierta e innovadora. Hechos y retos", en Modernización digital e innovación en la Administración de Justicia, (coord. Gómez Manresa, M. F., y Fernández salmerón, M.,), Ed. Thomson Reuters Aranzadi, Cizur Menor, 2019, pp. 291-313.
} 
digitalización de la Justicia en España, en las circunstancias actuales, parece insuficiente si realmente se apuesta decididamente por una justicia tecnológicamente avanzada y puntera.

Evidentemente, la Justicia es una organización compleja. En sentido amplio, incluyendo las formas extrajudiciales de resolución de litigios, casi inabarcable e imposible de enumerar en su despliegue, ya que, junto a la Administración de Justicia pública, asumida por el Poder Judicial y servida por juzgados y tribunales en el ejercicio constitucional de la función jurisdiccional que les atribuye el art. 117.3 de la Constitución Española habría que sumar las opciones arbitrales y de mediación ya disponibles y accesibles para el ciudadano. Estamos, por tanto, ante un tamaño, diversidad y heterogeneidad que solo pueden encontrar un punto de encuentro en una concepción omnicomprensiva e integradora de la Justicia, de forma además más perceptible hoy en día con la eclosión de las formas extrajudiciales de resolución de litigios tanto a nivel nacional como internacional. De ahí que el presente estudio baraje, precisamente, esos dos niveles. Además, la extensión e ideas centrales del mismo se condicionan por la situación actual que la pandemia ocasionada por el virus ${ }^{3}$ por el denominado COVID-19, sin ninguna duda pudiendo afirmar ya que se trata de un suceso que cambiará la sociedad, también la forma de impartir Justicia, y desde el cual la máxima del "distanciamiento social" como mandamiento preventivo influirá decisivamente en el proceso y en las formas extrajudiciales de resolución de litigios. Estas son, por tanto, las líneas maestras, una justicia digital tras la pandemia del Covid-19 y el desafío que implica, de forma especial en las opciones extrajudiciales, sobre las cuales sentamos las bases de nuestras reflexiones.

No puede negarse el esfuerzo ya realizado con diversos planes para la digitalización de la Justicia en nuestro país, e incluso con normas legales ad hoc como el caso de la Ley 18/2011 de uso de las tecnologías en la Administración de Justicia o el Real Decreto 396/2013, por el que se regulaba el Comité técnico estatal de la Administración de Justicia electrónica o la Ley 42/2015, por la cual se reforma la vigente Ley de Enjuiciamiento Civil a efectos de potenciar y obligar al uso de la tecnología en la Administración de Justicia. Fruto de los mismos son, a título de ejemplo, aplicaciones como LexNet $^{4}$ o los diferentes programas informáticos implementados en las Comunidades Autónomas -hubiera sido deseable una cierta uniformidad pero la concesión de competencias en materia de justicia a éstas y el asimétrico desarrollo e inversiones ha dado lugar a disparidad y diferencias notables- para aplicar sistemas de gestión procesal. En la ausencia de uniformidad estriba, concretamente, uno de los escollos que la justicia digital en España también ha de solventar en el periodo post-Covid19, por cuanto se aprecian notables diferencias de medios y resultados entre unos territorios y otros. No podemos permitir que en este aspecto pueda existir una Justicia digital de dos velocidades en nuestro

\footnotetext{
${ }^{3}$ Puede obtenerse más información con relación a la parte científica del virus en la web de la Organización Mundial de la Salud: https://www.who.int/es/emergencies/diseases/novel-coronavirus-2019.

${ }^{4}$ En virtud del RD 1065/2015, sobre comunicaciones electrónicas en la Administración de Justicia se procede a desarrollar y a actualizar la regulación de este sistema de comunicaciones electrónicas, para aquellas Administraciones usuarias del mismo.
} 
país, con Comunidades Autónomas punteras y otras con graves carencias, por cuanto se crean desigualdades que repercuten en el ciudadano que invoca su derecho a la tutela judicial efectiva. Personalmente entiendo que además se precisa un modelo de gestión digital de la justicia en España que sea común para todos sus territorios autonómicos, y un momento como el actual, de cambio y de reformulación del sistema, puede ser apropiado para este fin.

La Justicia digital tiene, como expone detalladamente GARCÍA COSTA ${ }^{5}$, fundamento constitucional. Este viene representado, según el autor de referencia, por la cláusula "sociedad democrática avanzada" del Preámbulo de la Constitución Española, como argumento que propicia la aplicación de las tecnologías de la información y la comunicación a los distintos ámbitos de acción estatal y que a su juicio "habilita para el aprovechamiento de las posibilidades derivadas de las TICs en el ámbito de los poderes del Estado y, todavía más, para legitimar las transformaciones que estas operan en el ámbito del Estado constitucional. Transformaciones que..., son esenciales en la esfera del e-Gobierno, y muy importantes, aunque no esenciales, en la de la e-Justicia" ${ }^{6}$. Disentimos en la precisión final, considerando que en la actualidad las transformaciones digitales en la Justicia son absolutamente esenciales en nuestra sociedad cuando se pretende ofrecer al ciudadano una eficaz tutela judicial efectiva. Y el derecho a la tutela judicial efectiva también demanda, actualmente, ofrecer al ciudadano una justicia digital, más accesible en muchos aspectos, más abierta y pública, más transparente, en definitiva, es un avance digno y acorde con la sociedad tecnológica, global e interconectada en que vivimos. La publicidad, la oralidad y la inmediación, como principios basilares del procedimiento, y también de los medios extrajudiciales de resolución de litigios, están perfectamente respaldados en un entorno digital siempre y cuando se equilibren perfectamente con el contrapeso necesario de la seguridad jurídica y tecnológica y la protección de datos personales. La justicia digital requiere de confianza, usabilidad y accesibilidad, siendo ambas una piedra de toque que puede chocar con la brecha digital que representan las carencias de formación, de aprendizaje en la utilización de TICs o de posible disponibilidad de medios para ello, tanto en el propio entorno de la Justicia como para los ciudadanos que pretendan dirimir sus litigios a través de ella. Incluso, puede topar con una palpable ineficiencia organizativa y legislativa, tal y como hemos apuntado anteriormente, y que puede ser otra rémora frente a la cual urgen medidas claras y precisas e implicación personal de todos los operadores jurídicos.

Comparto finalmente las atinadas observaciones de MARTÍNEZ DE SANTOS ${ }^{7}$ respecto a la intención del legislador en cuanto a implantar, con todas las consecuencias, un proceso judicial

\footnotetext{
5 GARCÍA COSTA, F.M., "Perfiles constitucionales de la justicia electrónica", Modernización digital e innovación en la Administración de Justicia, (coord. Gómez Manresa, M. F., y Fernández Salmerón, M.), ed. Thomson Reuters Aranzadi, Cizur Menor, 2019, pp. 29-ss.

${ }^{6}$ BUENO DE MATA, F., "E-Justicia: hacia una nueva forma de entender la justicia", Revista Internacional de Estudios de Derecho Procesal y Arbitraje, núm., 1, 2010, pp. 5-ss.

${ }^{7}$ MARTÍNEZ DE SANTOS, A., "Del juzgado y la sede física al proceso en línea”, Diario La Ley, núm., 9700, 2020.
} 
verdaderamente electrónico o limitarse meramente a poner parches ante la situación planteada por la pandemia del Covid-19, y que ha precisado tener que echar mano de las nuevas tecnologías ante la imposibilidad, por restricciones sanitarias, de llevar a cabo actos presenciales en los juzgados. ¿nos hemos planteado, en profundidad, diseñar e implementar un proceso judicial digital de principio a fin? Esta hipótesis no solo se sostiene sobre el diseño de una estructura tecnológica de gestión procedimental que respete las garantías procesales, los derechos fundamentales y los principios básicos del proceso y del procedimiento, sino que también demanda un cambio de mentalidad de quienes tienen relación con la administración de justicia. Quizá es momento, tal y como plantea el autor mencionado con la referencia del derecho comparado anglosajón, de definir el modelo a seguir. Si el modelo de implantación de las nuevas tecnologías en el proceso judicial va a consistir en incorporar estas a las estructuras existentes o bien si se va a disponer un modelo absolutamente nuevo de proceso judicial electrónico. La elección no es insustancial, puesto que supone determinar el verdadero modelo procesal de las próximas décadas.

Y en esta elección han de tener protagonismo preeminente los derechos fundamentales procesales. Como remarca CABEZUDO $\mathrm{BAJO}^{8}$, la eficacia en el empleo de mecanismos tecnológicos y telemáticos en el proceso, y fundamentalmente de cara al procedimiento ${ }^{9}$, no puede implicar vulneración de derecho fundamental alguno, sino un modo diferente de salvaguardarlos, siempre y cuando la tecnología aplicada sea la adecuada, al tiempo que se testan otros factores procesales de relevancia previstos en el ordenamiento jurídico como, según relata la autora, son la utilidad, seguridad, orden público y condición gravosa o perjudicial. Si la tecnología que digitalice la justicia no supera este crucial test, evidentemente no podrá ser aplicable.

\section{EL ENTORNO ACTUAL: UNA JUSTICIA POST-PANDEMIA}

Más allá de lo que la norma recientemente aprobada, Ley 3/2020, de 18 de septiembre, de medidas procesales y organizativas para hacer frente al COVID-19 en el ámbito de la Administración de Justicia (BOE del día 19 de septiembre), implica, en cuanto a cambios y adaptaciones en el sistema procesal, una reflexión global e integradora sobre la mejora de nuestra Justicia parece procedente. Ese es el objetivo del presente trabajo, fundamentalmente

\footnotetext{
${ }^{8}$ CABEZUDO BAJO, M.J., “Avance hacia un juicio penal íntegramente telemático mediante un uso más generalizado de la videoconferencia: eficiencia y derechos fundamentales", Revista General de Derecho Procesal, núm. 52, 2020.

${ }^{9}$ En el Documento de la Fiscalía General del Estado, "Propuesta de 60 medidas para el plan de desescalada en la administración de justicia tras la pandemia de coronavirus covid-19", p.2, destaca como algunos de los objetivos generales de las medidas que propone de manera específica: la agilización procesal, a través de la armonización de la eficacia procedimental, la optimización de los recursos personales y la tutela judicial efectiva sin merma de derechos, que garantice un proceso sin dilaciones indebidas y la dotación de medios materiales y tecnológicos adecuados, como el expediente digital o el sistema de gestión procesal único, pues una de las principales carencias que esta crisis ha revelado ha sido, precisamente, la tecnológica.
} 
orientado a que la tecnología y las ventajas que aportan las herramientas de telecomunicación y desempeño de tareas a distancia encuentren un acomodo seguro y fiable en el ámbito de la Justicia en España, tanto en el marco procesal como fundamentalmente, y ahí centraremos de forma más intensa nuestras valoraciones, en las vías extraprocesales.

Ciertamente puede ser, lo anterior, consecuencia, en parte, de que hemos llevado a cabo, incluso de forma inesperada y apresurada, determinados cambios de comportamiento, relación y desempeño de labores jurídicas y procesales debido a la irrupción de la pandemia mundial ocasionada por el virus SARS-CoV-2 (popularmente conocido como "coronarivus o Covid19). Desde las primeras consecuencias de la pandemia, a nivel judicial, se comenzaron a esbozar propuestas para una mejora de la Justicia. De este modo, el Consejo General de Poder Judicial en su "Primer Documento de trabajo sobre medidas organizativas y procesales para el Plan de Choque en la Administración de Justicia tras el Estado de Alarma" situó como una de las líneas de acción fundamentales la incorporación efectiva de la tecnología al proceso y la digitalización de la Justicia. El citado documento es meridianamente explícito en sus páginas 5 y 6 , en relación con el orden jurisdiccional civil al indicar que uno de los bloques temáticos de propuestas se dirige "a la adopción de medidas legislativas urgentes que permitan mayor flexibilidad en las actuaciones, buscando una tramitación más expeditiva, evitando ralentizaciones e incrementando el uso de medios tecnológicos a nuestro alcance", y en la página 9, en relación con el orden jurisdiccional penal avanza su batería de medidas tendente a "la incorporación de las nuevas tecnologías a la Jurisdicción, siendo aún un proceso no acabado, permite aligerar algunos trámites, practicar pruebas sin causar molestias a las personas y permite documentar actuaciones procesales esenciales. En este sentido, se propone que en determinados ámbitos o circunstancias las sentencias puedan dictarse oralmente, sin necesidad de su documentación posterior, es decir, que, en el momento mismo de finalizar el juicio, el juez pueda pronunciar su decisión y en ese mismo momento expresar la fundamentación fáctica y jurídica de la misma. Al estar recogida tal fundamentación en un soporte audio y/o visual queda garantizado el derecho de defensa respecto de un eventual recurso de apelación".

Aun así, y sin negar el efecto acelerante que ha tenido la pandemia, la conjunción entre tecnología y Justicia ya se venía produciendo, sin perjuicio, de que requería, y requiere, de una mayor apuesta y una mejor implementación. La Justicia del siglo XXI será eminentemente digital y telemática ${ }^{10}$, de eso no cabe duda. En un mundo tecnológico, en el que se trabaja a todos los niveles, públicos y privados, en entornos electrónicos, la justicia no puede ir contracorriente por puras razones de adaptación a la sociedad en la que se enmarca, sostenibilidad y la propia exigencia de mejora y eficiencia que como servicio público para la ciudadanía han de exigirse de ella para dispensar una tutela judicial verdaderamente efectiva

\footnotetext{
${ }^{10}$ Entendida según la segunda acepción de este término que refiere el Diccionario de la Lengua Española, Real Academia Española (del.rae.es) como "aplicación de las técnicas de la telecomunicación y de la informática a la transmisión de información computerizada”.
} 
acorde con los tiempos en los que se imparte. Y además con una tutela judicial integradora y amplia, una tutela de la Justicia, que abarque tanto al proceso como a las soluciones extrajurisdiccionales de litigios desde el máximo y mayor aprovechamiento de las opciones electrónicas sin merma de las garantías de seguridad jurídica y respeto pleno a los derechos fundamentales de los justiciables.

El contexto de la justicia, particularmente en España en 2020, puede determinarse, entre otros factores, por la concurrencia de dos factores. En primer lugar, un necesario impulso digital y tecnológico de la Justicia, en proceso de asentamiento paulatino, aún tímido pero creciente. El segundo factor es el auge de la utilización de soluciones extrajudiciales de litigios como complemento a la vía procesal. Apogeo que viene sustentado fundamentalmente por la dotación de marcos normativos de referencia, la concienciación de los operadores jurídicos en su utilización y la capacitación y formación de profesionales que asuman funciones arbitrales o mediadoras. El arbitraje o la mediación, poco a poco, litigio a litigio, van extendiéndose como una gradual mancha de aceite sobre el tablero de la Administración de Justicia. Verdaderamente de forma aún incipiente, todavía con un exiguo peso cuantitativo -que no, en ocasiones, cualitativo- en el monto global de los litigios que han de resolverse en nuestro país, pero marcando una línea de ruptura y avance en el panorama procesal de estas dos primeras décadas de siglo. Línea que está llamada, salvo cambios de rumbo inesperados, a consolidarse y que puede encontrar en la tecnología a su gran aliada para su impulso definitivo, merced a la flexibilidad y adaptabilidad que presentan los medios extrajudiciales de resolución de litigios como característica fundamental y principal.

Habitualmente se circunscribe casi de forma automática, al hacer referencia a la conjunción entre tecnología y medios extrajudiciales de resolución de litigios a los conflictos propios de materias de derecho privado, y por tanto vinculados al orden jurisdiccional civil. La visión que pretendemos ofrecer en este trabajo es amplia e integradora, extendiendo el desafío de coordinar y rubricar legalmente la implantación de medidas de innovación tecnológica en el ámbito de la Justicia con las soluciones extrajudiciales de litigios, a los diferentes órdenes jurisdiccionales, apoyándonos, bien es cierto, en muchas de las referencias y situaciones reales ya experimentadas que, en puridad, han nacido en el marco más idóneo para la desjudicialización del litigio, como es el del derecho privado y el ejercicio de la autonomía de la voluntad de las partes en relación con derechos disponibles y para los cuales optan por soluciones no vinculadas al proceso judicial.

Retomando las valoraciones sobre el contenido y la proyección de la norma recientemente publicada - Ley 3/2020-, y que propicia un avance para el establecimiento de medidas organizativas y tecnológicas, puede ser la espoleta que, desde la premisa de la salvaguarda de la salud por motivo de la pandemia causada por el Covid19, impulse la realización de actuaciones telemáticas siempre desde el mantenimiento de las debidas garantías procesales y de los derechos de las partes en el proceso, de forma particular el respeto absoluto al derecho de defensa y al principio de contradicción. El art. 14 de la citada Ley 3/2020, rubricado bajo el título "celebración de actos procesales mediante presencia telemática", señala como principio 
general de actuación procesal, hasta el 20 de junio de 2021, la realización preferente mediante presencia telemática de comparecencias, declaraciones y vistas así como la de todos los actos procesales, siempre que los órganos jurisdiccionales y las fiscalías acrediten tener a disposición los medios técnicos necesarios para ello, estando constituidos los juzgados y tribunales en su sede. Sobre este último inciso, entendemos, que la presencia del titular del órgano jurisdiccional unipersonal o de los integrantes del órgano colegiado, para la realización de las actuaciones telemáticas enumeradas debe producirse desde su sede física como juzgado o tribunal.

Se habilita, por tanto, la realización de actos procesales, incluso de forma preferente, mediante el empleo de sedes telemáticas, sin perjuicio, particularmente en el orden jurisdiccional penal y por la concurrencia de determinados derechos fundamentales, de mantener la imprescindible presencia física ${ }^{11}$ del investigado o encausado en los casos de procesos penales por delito grave, en la audiencia prevista para la adopción de la medida cautelar de prisión provisional o, por ejemplo, en la celebración del juicio cuando alguna de las acusaciones solicite una pena de prisión superior a los dos años -salvo que concurran causas justificadas o de fuerza mayor que lo impidan-. En cambio, si se difiere a su realización telemática las deliberaciones de los órganos jurisdiccionales colegiados, siempre que se cuente con medios técnicos para ello (apartados segundo y tercero del art. 14 de la Ley 3/2020).

En cualquier caso, el garantismo ha de presidir la realización de cualquier actuación procesal mediante sistemas telemáticos (así lo refrenda expresamente el art. 14.5 de la citada Ley de 2020), y de forma particular el derecho de defensa de acusados e investigados en los procedimientos penales, el derecho a la asistencia letrada efectiva, a la interpretación y traducción y a la información y acceso a los expedientes judiciales. Cualquier actuación conducida por medios tecnológicos, por decisión del juez o del letrado de la Administración de Justicia, podrá incorporar la asistencia presencial en la sede del juzgado o tribunal de los comparecientes que estime necesarios.

Pudiera parecer que esta reforma legal, con ciertos visos de interinidad, puesto que la propia ley predetermina su vigencia por un plazo delimitado y relativamente corto -hasta mediados del año 2021-, si pueda representar, paradójicamente, el escenario en el cual han de desenvolverse los procesos judiciales de los próximos lustros, con un importante apoyo y vinculación tecnológica en su planificación y presencia física. Ante esta tesitura, pretendemos valorar dos concretas repercusiones, que planteamos como conjeturas, para señalar la ruta hacia donde puede discurrir el modelo de Justicia que, como influencia de la pandemia producida por el Covid19, se atisba eminentemente tecnológica, flexible, abierta y a distancia. La primera en relación a los posibles cambios o matices que la apuesta por una mayor cobertura y realización tecnológica de actuaciones procesales pueda tener sobre el principio de inmediación,

\footnotetext{
${ }^{11}$ Supuestos para los cuales también requiere la Ley la inexcusable presencia física de su defensa letrada, a petición de esta o del propio acusado o investigado.
} 
fundamentalmente en materia de prueba al habilitarse la realización de la vista también mediante soluciones telemáticas. En segundo término, trataremos de situar las posibles ventajas que las vías extrajudiciales de litigios presentan, de forma general, en relación al proceso judicial y el empleo de la tecnología y la realización de sus actos y procedimientos sin la necesidad de una presencia física directa de los implicados.

\section{3. ¿EL PRINCIPIO DE INMEDIACIÓN SE VIRTUALIZA?}

\subsection{El principio de inmediación: significado y alcance}

Indicaba CABEZUDO RODRÍGUEZ" que inmediación “expresa convencionalmente proximidad o contigüidad a algo, cercanía física a un objeto material que es susceptible de convertirse en un método de conocimiento e interacción con el objeto de que se trate". Desde esta concepción general se proyecta como uno de los principios nucleares del procedimiento ${ }^{13}$, considerada, ya en este concreto marco, como la directa relación entre actividad procesal y presencia del juez ${ }^{14}$ o tribunal competente. Implica una concurrencia temporal y espacial síncrona, y no interpuesta, entre quien aporta datos al proceso, esos datos y quien recibe ese material para su valoración a través del pertinente acto procesal.

Encuentra su expresión procesal más crucial y palpable, que no la única y exclusiva, en el momento de la práctica de la prueba en la vista, por cuanto tras las alegaciones de las partes, el juez o tribunal percibe de forma directa y no interpuesta el resultado de los medios de prueba practicados, para su valoración y con ello la plasmación de su convicción respecto a los hechos controvertidos, de forma también lo más próxima posible temporalmente, en la sentencia. La inmediación, como principio procedimental, se ha asociado tradicionalmente a otro de los principios procedimentales estructurales como es la oralidad, pero sin que ambos se identifiquen absolutamente, aunque este segundo propicie la operatividad del primero ${ }^{15}$. De su

\footnotetext{
${ }^{12}$ CABEZUDO RODRÍGUEZ, N., “Aproximación a la teoría general sobre el principio de inmediación procesal. De la comprensión de su trascendencia a la expansión del concepto", Oralidad y escritura en un proceso civil eficiente, edits. F. Carpi y M. Ortells Ramos, vol. 2, Valencia, 2008, p. 317.

${ }^{13}$ HERRERA ABIÁN, R., La inmediación como garantía procesal, ed. Comares, Granada, 2006.

${ }^{14}$ El principio de inmediación, como exigencia ineludible de presencia judicial directa en las diligencias judiciales que así lo requieran ha sido destacado por el Consejo General del Poder Judicial de forma particular en la necesidad de que los jueces estén presentes en la práctica de las pruebas. El Libro Blanco de la Justicia (CGPJ), recogía esta exigencia en su p. 88 "No puede dejar pasar esta oportunidad para insistir en la necesidad y obligación inexcusable de los jueces de cumplir el ordenamiento procesal vigente. Resulta preocupante conocer en las muchas entrevistas realizadas que los jueces no cumplen con el principio de inmediación en general y en actos como éste en particular. Obviamente, la primera obligación del juez es cumplir la ley. Es cierto que hay que definir en forma más razonable los supuestos en los que la presencia del juez es inexcusable y eliminar de entre éstos aquellos en los que su intervención personal es superflua. Pero mientras que la ley exija la presencia del juez, por más que sea criticable, en ésta y en todas las ocasiones en que así se ponga, deberá estar presente".
}

${ }^{15}$ CHIOVENDA, G., Ensayos de Derecho Procesal Civil, Buenos Aires, 1949, p. 254. 
conjunción se irradian efectos ventajosos, como advierte GIMENO SENDRA ${ }^{16}$, en cuanto al descubrimiento de la verdad material que subyace en el objeto del litigio. La interacción directa e inmediata entre juzgador y material probatorio (partes, testigos, peritos) a la hora de valorar no sólo el contenido de lo expuesto, sino la forma de exponer o contestar a las interpelaciones del juzgador y de los defensores de las partes, así como la posición activa del juzgador preguntando o requiriendo explicaciones contribuye, como remarca el autor citado, de una manera decisiva al principio de inmediación.

Frente a estas ventajas no podemos obviar algunos inconvenientes, e incluso llegar a la conclusión de que, en cierto modo, la inmediación está, o ha estado, sobrevalorada ${ }^{17}$. Destacamos uno por encima del resto, por su incidencia en la sociedad contemporánea. Me refiero al sesgo y al influjo inconsciente que puede crear en el juzgador como consecuencia de la inmediación, cuando ésta implica el contacto directo con la fuente de prueba y ello supone un examen directo y personal del juzgador respecto a quienes prestan testimonio en el proceso cuya valoración ha de establecer y fijar el órgano jurisdiccional. Determinada presencia, actitud, forma de hablar o de vestir, procedencia o sexo de los intervinientes en el proceso podrían generar estímulos, sesgos o conclusiones erróneas, por sí mismas, al juzgador cuando más que el contacto directo con la persona y su apariencia, el juzgador ha de valorar lo que manifiesta.

La inmediación también está enlazada, procesalmente hablando, con el principio de contradicción, facilitando la presencia de los intervinientes en el acto procesal y la posibilidad de alegar, cuando la ley así lo contemple, cuanto convenga a su posición o situación procesal. Básicamente se refiere a las partes y a la posibilidad de conferirles una opción al enfrentamiento dialéctico para conocer sus argumentos y la manifestación ante el juzgador de la valoración que el acto procesal, llevado a cabo con todas las garantías, les ha deparado. Desde el principio de contradicción, y la igualdad de armas procesales que éste determina, se deriva la necesidad de asegurar, por el juzgador, que las partes dispongan de los mismos medios procesales para hacer valer y exponer sus alegaciones, con idénticos derechos, obligaciones y cargas procesales en lo que a esta cuestión se refiere, salvo modulaciones y restricciones legalmente establecidas. En este sentido, la virtualización del principio de inmediación, en cuanto determine realizar actos procesales en sedes telemáticas, ha de tener como exigencia inexcusable la verificación de que todos los intervinientes disponen de mecanismos adecuados e idóneos para ello y, por tanto, para garantizar los principios de contradicción e igualdad de armas en plenitud.

\footnotetext{
${ }^{16}$ GIMENO SENDRA, V., Fundamentos del Derecho Procesal, Ed. Cívitas, Madrid, 1981, p. 227.

${ }^{17}$ NIEVA FENOLL, J., "Oralidad e inmediación en la prueba: luces y sombras", Civil Procedure Review, vol.1,

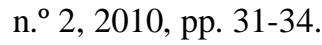


Hasta el momento, y salvo la utilización puntual de videoconferencias ${ }^{18}$ en relación a la prueba de interrogatorio de la parte, de declaración de testigos o, más excepcionalmente, la presentación oral del informe del perito, la inmediación se entendía desde un parámetro físico de no interposición, elemento que vendría a ser matizado con la realización de actos procesales en vía telemática, al tener que recurrir a un elemento interpuesto como es la tecnología (en modo audio y video) que propicia la realización a distancia, sin presencia física, de los actos procesales. Esto nos conduce a la interrogante que intitula este apartado: ¿se virtualiza el principio de inmediación $?^{19}$.

\subsection{Transición hacia otra dimensión de la inmediación: la virtualización de las actuaciones procesales}

Para avanzar la respuesta, y con ello el matiz que introducimos al principio de inmediación para convertirlo en "inmediación virtualizada", acudimos al planteamiento de ORTELLS RAMOS 20 cuando afirma que "las nuevas tecnologías de la informática y las telecomunicaciones han abierto posibilidades de cambios en las formas de realización de los actos procesales". Desde la constatación del citado autor, tomamos la base para determinar que esos cambios en las formas de realización de actos procesales también nos pueden conducir, en opinión personal, a un cambio, o al menos a una actualización, en la denominación y aplicación de principios procesales del procedimiento como es el caso que nos atañe.

Vayamos por partes. En primer lugar, en cuanto a que la tradicional asociación entre principio de inmediación y oralidad consideramos que no se ve afectada en modo alguno, aun produciéndose una virtualización de la inmediación al utilizarse soluciones telemáticas para la realización de actos procesales. En modo alguno impide el recurso tecnológico las alegaciones orales de las partes, del juez o tribunal y del resto de participantes en el acto procesal. Más aún, insistimos, cuando inmediación y oralidad no son conceptos idénticos a nivel procesal. Un procedimiento puede estar perfectamente regido por la inmediación cuando el órgano jurisdiccional realiza y valora la práctica de la prueba respecto de documentos escritos. Por otra parte, la conjunción entre inmediación y oralidad reporta determinados beneficios procesales, fundamentalmente en aras a la fijación de los hechos probados y con ello a la determinación del objeto del litigio y la relación jurídico material de fondo. La interacción ${ }^{21}$ entre juzgador,

\footnotetext{
${ }^{18}$ Véase el reciente trabajo de CABEZUDO BAJO, M.J., "Avance hacia un juicio penal íntegramente telemático mediante un uso más generalizado de la videoconferencia: eficiencia y derechos fundamentales", cit., pp. 1-ss.

${ }^{19}$ Línea de pensamiento que ha planteado con anterioridad BUENO DE MATA, F., "El uso de la videoconferencia en el proceso penal: ¿existencia de la inmediación virtual?, Estudios actuales en Derecho y Ciencia Política, (Coord. Carrizo González-Castell, A.), ed. Andavira, Santiago de Compostela, 2011, pp. 33-49.

${ }^{20}$ ORTELLS RAMOS, M., Introducción al Derecho Procesal, VV.AA., Tirant lo Blanch, 10ª ed., Valencia, 2020, p. 360

${ }^{21}$ NIETO GARCÍA, A.J., "El principio de inmediación, el lenguaje no verbal y gestual y las microexpresiones faciales”, Diario La Ley, núm., 9491, 2019.
} 
partes y terceros intervinientes contribuye notablemente la averiguación de los hechos y a su interrelación con la relación jurídico material sobre la cual también ha de pronunciarse el órgano jurisdiccional en la sentencia. La incertidumbre aparece ahora en cuanto al posible resultado y consecuencias que pueda deparar la interposición de un elemento tecnológico de comunicación a distancia entre juzgador e intervinientes en el acto procesal, y si ello puede condicionar o menoscabar los beneficios de la inmediación.

Es evidente, por tanto, que la inmediación es imprescindible para el desarrollo de determinadas actuaciones procesales, y que, en caso de no observarse, puede derivar en una nulidad de pleno derecho de las actuaciones en que no se haya seguido la misma, por contravenirse o lesionarse directamente determinados derechos fundamentales y garantías procesales, a tenor de las previsiones del art. 240 LOPJ. Contrario sensu no implica, y la propia Ley 3/2020 es una habilitación expresa para posibilitarlo, la imposibilidad de realizar actos procesales válidos sin inmediación o, en el caso que nos ocupa, con una inmediación virtualizada mediante el empleo de mecanismos de comunicación a distancia o telemática ${ }^{22}$. De hecho, ya se vienen produciendo actos procesales en sede virtual, sean actos típicos sin inmediación -como la presentación de la demanda o la querella- o con inmediación interpuesta -como la realización de videoconferencias para que presten declaración las partes u otros intervinientes en el proceso-. Incluso actos con consecuencias procesales directas, como la ratificación de la petición de separación o divorcio consensual, prevista en el art. 777.3 LEC, mediante sesión en que las partes se identifican con DNI, sus abogados están presentes y una vez que se comprueba la libre voluntad ya no hay necesidad de acudir al juzgado en persona, con un notable ahorro de tiempo y costes para todos con el mismo resultado. Inmediación virtualizada, en definitiva, pero igual de valida y efectiva.

La clave que permite avanzar en la dirección correcta, y en la implementación de una inmediación virtualizada en el proceso es el pleno respeto a los derechos fundamentales ${ }^{23}$ procesales y a las garantías del proceso. Dicha salvaguarda tiene en la interacción judicial su gran estandarte, por cuanto la exigencia de que jueces y tribunales presencien la actividad jurisdiccional es garantía de su regularidad y adecuación a las exigencias procesales. De este modo, ya la Ley de Enjuiciamiento Civil vigente potencia la aplicación del principio de inmediación en los procesos declarativos, augurando en su Exposición de Motivos que la Ley "diseña los procesos declarativos de modo que la inmediación, la publicidad y la oralidad hayan

\footnotetext{
${ }^{22}$ SAGÜILlO TEJERINA, E., "El principio de inmediación y las nuevas tecnologías en el juicio penal”, $L a$ Justicia digital en España y la Unión Europea, (coord. Arrabal Platero, P., García Molina, P., Conde Fuentes, J., dir. Serrano Hoyo, G.), ed. Atelier, Barcelona, 2019, pp. 207-218.

${ }^{23}$ En este mismo sentido incide el Apartado 6 de la Conclusiones del Consejo de la Unión Europea en su documento "Acceso a la Justicia: aprovechar las oportunidades de digitalización", referencia 2020/C342I/01, Diario Oficial de la Unión Europea de 14 de octubre, señalando que "las tecnologías digitales se pueden utilizar en los sistemas judiciales para promover el cumplimiento de las normas del Estado de Derecho y el ejercicio y el respeto de los derechos fundamentales".
} 
de ser efectivas". Situación que se plantea a la inversa en la segunda instancia, donde, como advierte DEL POZO PÉREZ ${ }^{24}$, se aprecia una clara quiebra del principio de inmediación en sentido estricto "puesto que el órgano jurisdiccional ad quem, que dicta, por tanto, la Sentencia, puede apartarse, respetando la legalidad, de la valoración fáctica del juez a quo sin necesidad alguna de practicar nueva prueba sobre los hechos controvertidos; todo ello debido el restringido régimen probatorio en la segunda instancia”.

Apreciamos entonces como, por ejemplo, el art. 137 LEC exige la presencia del titular del órgano jurisdiccional en el acto de práctica de la prueba bajo sanción de nulidad del mismo, al igual que el art. 238.5 LOPJ prevé la nulidad del juicio oral (vista) llevada a cabo sin la preceptiva intervención del Letrado de la Administración de Justicia, cuya labor de fedatario público acredita, entre otras cuestiones, la presencia inmediata del juez. En uno y en otro caso la habilitación de recursos telemáticos, acordes con la protección de datos personales y suficientemente verificados para avalar la actividad procesal desarrolladas, es factible y concuerda con una inmediación virtualizada.

En este entorno de inmediación virtualizada puede practicarse la prueba en unidad de acto, art. 290 LEC, y se mantienen intactas las facultades del órgano jurisdiccional de dirección de los debates (art. 186 LEC), interrogatorio de partes y testigos, reconocimiento judicial, reproducción de palabras, imágenes y sonido, cifras, datos, explicaciones, rectificaciones y ampliaciones del dictamen pericial -tal y como dispone el art. 289.2 LEC-. La intervención activa del órgano jurisdiccional en sede virtual o telemática también habilita la formulación de preguntas a intervinientes (arts. 306 y 372.2 LEC) o la petición de informes adicionales a las partes (433.3), legitimando con ello perfectamente la exigencia del art. 194.1 LEC en cuanto a que solo "el juez o Magistrado que ha presenciado la vista está legitimado para dictar la pertinente resolución". La alusión a haber presenciado la vista, no requiere, en una interpretación acomodada a la realidad actual, una presencia física directa, sino que también puede asumirse en esta legalidad una presencia "telemática". Además, en los supuestos que la ley contempla que no pueda llevarse a cabo la actividad probatoria en juicio en unidad de acto o en la propia vista por las condiciones de práctica de dicho medio de prueba, también es plenamente realizable a través de una inmediación virtualizada con el empleo de recursos telemáticos para, por ejemplo, el interrogatorio de una persona enferma (pensemos en los casos actuales de aislamiento por Covid-19), la propia prueba pericial si el órgano jurisdiccional no considera imprescindible la presencia del perito en sala, o las declaraciones testificales de personas jurídicas y de entidades públicas (art. 381 LEC) o el interrogatorio de la Administración pública normativamente regulado en el art. 315 LEC.

\footnotetext{
${ }^{24}$ DEL POZO PÉREZ, M., "La quiebra de la inmediación en la segunda instancia del proceso civil”, Oralidad y escritura en un proceso civil eficiente, (edits. Carpi, F., y Ortells Ramos, M.), vol. 2, Valencia, 2008, p. 237.
} 
La celebración de actuaciones procesales de forma telemática, particularmente el juicio y con ello la práctica de la prueba, acarrea la disyuntiva de las posibles colisiones que ello pueda tener, tal y como hemos afirmado anteriormente, con principios como la inmediación, la oralidad o la contradicción, a cambio, bien es cierto, de una mayor celeridad en la realización de determinadas actuaciones. Personalmente considero que, respetando garantías y derechos fundamentales -defensa, presunción de inocencia, asistencia letrada, proceso público con todas las garantías, utilización de los medios de prueba pertinentes, etc.- la dispensa al ciudadano de tutela judicial efectiva mediante actos procesales telemáticos no tiene por qué menoscabar dicho derecho, desde su vertiente de acceso a la justicia.

Así puede comprobarse en una reciente resolución de la Audiencia Provincial de Barcelona ${ }^{25}$, Sentencia de 21 de septiembre de 2020, en la cual se establece que la celebración del juicio por videoconferencia, como consecuencia del Covid-19, no afecta al derecho de defensa del encausado ya que las condiciones de audio y video eran óptimas y no daban lugar a ningún tipo de indefensión. La Audiencia desestima el recurso de nulidad del juicio interpuesto por indefensión, dado que como consecuencia del Estado de Alarma debió celebrarse por videoconferencia la vista al no poder trasladarse al encausado desde el centro penitenciario al hallarse Barcelona en fase 1 y con confinamiento absoluto. Apoyaba legalmente dicha decisión el art. 19 del Real Decreto-ley 16/2020, de medidas procesales y organizativas para hacer frente al Covid-19 en el ámbito de la Administración de Justicia que, como hemos expuesto, dispuso entonces que durante la vigencia del estado de alarma y hasta tres meses después de su finalización, los actos de juicio, comparecencias, declaraciones y vistas y, en general, todos los actos procesales se realizaran preferentemente mediante "presencia telemática". Circunstancia esta que se ve confirmada por las previsiones de la Directiva (UE) 2016/343, de 9 de marzo de 2016, por la que se refuerzan en el proceso penal determinados aspectos de la presunción de inocencia y el derecho a estar presente en el juicio, que no impone siempre y en todo caso la presencia física de la persona acusada en la Sala de vistas, cuando concurren razones excepcionales que justifiquen su intervención a distancia -como era el caso-.

En otro orden de cosas, no olvidemos, tampoco, que hay miles de procesos, especialmente en el ámbito del orden jurisdiccional civil, en que la cuestión a resolver es meramente jurídica, donde no hay hechos controvertidos -que por tanto no precisan de prueba y con ello tampoco precisan de la celebración de la vista para la práctica de la misma- o donde existiendo controversia en cuanto a los hechos la totalidad de la prueba es documental. Procedimientos, estos antes reseñados, en que el procedimiento telemático puede aportar rapidez y eficacia para una pronta, e igualmente justa, solución al litigio. Piensen, en estos casos, en reclamaciones de cantidad, determinación de la legalidad o carácter abusivo de cláusulas contractuales o ejecuciones hipotecaria, por citar algunos de los supuestos más ilustrativos. Similar es la situación que acontece en numerosos asuntos del orden contencioso-administrativo y del social,

\footnotetext{
${ }^{25}$ Referencia La Ley 119526/2020.
} 
con litigios en que la controversia es únicamente de carácter jurídico material, y apenas requieren de prueba o en su caso los hechos controvertidos se pueden determinar desde la concurrencia de pruebas documentales.

La particularidad del proceso penal, y las peculiaridades procedimentales que en este orden jurisdiccional se establecen, requieren de un análisis individual ${ }^{26}$. Manteniendo como principios informadores procedimentales del proceso penal, plena validez y aplicabilidad, los de inmediación, oralidad y contradicción (art. 229 LOPJ), en este concreto ámbito adquieren, si cabe, una mayor relevancia por cuanto a presencia del órgano jurisdiccional es donde han de producirse la práctica de diligencias, en la fase de instrucción, y de pruebas, en la de enjuiciamiento, que puedan acreditar la autoría y responsabilidad del hecho delictivo. Firme ha sido la postura del Tribunal Constitucional en este sentido, por ejemplo, en la Sentencia 16/2009, de 26 de enero, determinando que "la garantía de inmediación consiste en que la prueba se practique ante el órgano judicial al que corresponde su valoración", sin perjuicio de que la propia LECrim contempla considerables ejemplos que no requieren de inmediación para la plena validez de la actuación procesal, como los casos de los arts. 306, 448, 710 o 714 LECrim. Complementa esa visión ofrecida por el máximo garante constitucional, la doctrina jurisprudencial del Tribunal Supremo (Sentencia 331/2019 de 27 de junio), apreciando, por ejemplo, que "en el concreto supuesto de utilización de la videoconferencia en la fase de instrucción, permite un mejor conocimiento de este principio en cuanto posibilita que el Juez o Tribunal que conoce del asunto presencie directamente la práctica de la prueba, en los casos de auxilio judicial tanto nacional como internacional incluso, en este último caso, posibilitando la directa aplicación de la legislación nacional en la práctica de la diligencia de que se trate". Sobre el juicio oral equipara jurídicamente la presencia física con la virtual ${ }^{27}$.

Más aún, puede ser recomendable la utilización de medios telemáticos en el proceso penal cuando, debido a las circunstancias concurrentes, así lo aconseje la seguridad de la víctima y la protección para evitarle una victimización secundaria, la defensa del orden público, la prevención de otros delitos o la protección a la vida, libertad y seguridad de otros intervinientes en el proceso, tal y como ya anticipó la Sentencia del Tribunal Europeo de Derechos Humanos de 5 de octubre de 2006, caso Marcello Viola vs. Italia, convalidando para ello la utilización de la videoconferencia ${ }^{28}$ como forma de realización de actos procesales en sede telemática. Recordemos que la legislación positiva aplicable dispone expresamente la habilitación, art. 731

\footnotetext{
${ }^{26}$ Vid. el trabajo de LÓPEZ RUÍZ, F., "Notas entorno al principio de inmediación en el proceso penal. Una aproximación epistemológica”, Revista General de Derecho Procesal, núm., 40, 2016.

${ }^{27}$ Vid., CABEZUDO BAJO, M.J., “Avance hacia un juicio penal íntegramente telemático mediante un uso más generalizado de la videoconferencia: eficiencia y derechos fundamentales", cit., p. 26.

${ }_{28}$ MONTESINOS GARCÍA, A., La videoconferencia como instrumento probatorio en el proceso penal, Ed. Marcial Pons, Madrid, 2009 y TAVOLARI OLIVEROS, R., "La videoconferencia como mecanismo de comparecencia y la garantía del debido proceso" Revista Uruguaya de Derecho Procesal, núm., 1, 2006, pp. 113130.
} 
bis LECrim., para que el tribunal "de oficio o a instancia de parte, por razones de utilidad, seguridad o de orden público, así como en aquellos supuestos en que la comparecencia de quien haya de intervenir en cualquier tipo de procedimiento penal como imputado, testigo, perito, o en otra condición resulte gravosa o perjudicial, y, especialmente, cuando se trate de un menor, podrá acordar que su actuación ${ }^{29}$ se realice a través de videoconferencia ${ }^{30}$ u otro sistema similar que permita la comunicación bidireccional y simultánea de la imagen y el sonido, de acuerdo con lo dispuesto en el apartado 3 del artículo 229 de la Ley Orgánica del Poder Judicial”.

Verdaderamente la Ley 3/2020 brinda, en cualquier caso, un marco legal de apoyo a la evolución de la inmediación hacia una inmediación virtual, por cuanto contempla expresamente la opción de desarrollar actos procesales mediante herramientas tecnológicas y en sedes telemáticas que replican la sede judicial física. Será de interés ver como se va implementado esta posibilidad desde la aplicación de la "Guía para la celebración de actuaciones judiciales telemáticas" 31 elaborada desde el CGPJ. Es un paso adelante en la incorporación y empleo de las nuevas tecnologías en la actividad jurisdiccional que sitúa, ya de antaño, el art. 230 LOPJ, como obligación para juzgados y tribunales (también, no lo olvidemos, para las fiscalías), eso sí, siempre que estén, literalmente según el precepto, "puestos a su disposición para el desarrollo de su actividad y ejercicio de sus funciones" con las limitaciones que a la utilización de tales medios se establecen tanto en la propia LOPJ como en la normativa orgánica de protección de datos personales. Por todos es sabido la carencia estructural en medios materiales y tecnológicos de muchos de los juzgados y tribunales de nuestro país, por lo que esta apuesta, que la Ley 3/2020 dispone, exige una importante inversión y adaptación de los juzgados, de los sistemas y plataformas tecnológicas y de los medios a disposición, y que solo podrá llegar a ser verdaderamente productiva y fecunda si toma como punto de partida una planificación global de una Administración de Justicia tecnológica y puntera y no mediante parches aislados a todos los niveles. Deben atenderse las prevenciones realizadas al efecto en el art. 230.6 LOPJ en cuanto a que "los sistemas informáticos que se utilicen en la Administración de Justicia deberán ser compatibles entre sí para facilitar su comunicación e integración, en los términos que determine el Comité Técnico Estatal de la Administración de Justicia Electrónica. La definición y validación funcional de los programas y aplicaciones se efectuará por el Comité Técnico Estatal de la Administración de Justicia Electrónica".

\footnotetext{
${ }^{29}$ FERNÁNDEZ-FÍGARES MORALES, M.J., "El principio de inmediación ante las declaraciones obtenidas mediante la captura y retransmisión audiovisual en el proceso penal", Era Digital, Sociedad y Derecho, (coord., Arrabal Platero, P., y. Doig Díaz, dir., Fuentes Soriano, O.), ed. Tirant lo Blanch, Valencia, 2020, pp. 467-479.

${ }^{30}$ Planteándose en el panorama actual su extensión y empleo de forma más intensa, como expone MAGRO SERVET, V., "Hacia el uso habitual de la videoconferencia en las vistas judiciales. Aprovechando las enseñanzas del Coronavirus. De la excepción a la regla general del art. 19 RD 16/2020, de 28 de abril”, Diario La Ley, núm. 9639, 2020.
}

31 Accesible en: http://www.poderjudicial.es/cgpj/es/Poder-Judicial/En-Portada/La-Comision-Permanenteaprueba-una-Guia-para-la-celebracion-de-actuaciones-judiciales-telematicas (última consulta 13.10.2020). 
Del propio art. 230 LOPJ podemos extraer asimismo tres importantes elementos que ofrecen la transición del principio de inmediación al de inmediación virtualizada. A saber:

a) Las actuaciones procesales, orales -grabación de vistas o celebración de comparecencias, etc.documentadas en soporte digital no podrán transcribirse (art. 230.3 LOPJ), salvo en los casos expresamente previstos por ley, de lo que se infiere que un acto realizado con inmediación virtualizada, gracias a las nuevas tecnologías en cuyo entorno se produce ha de preservarse íntegro por cuanto su valor procesal viene dado por lo almacenado en el soporte correspondiente que recoge dicho acto. Por tanto, un acto procesal en inmediación virtualizada no precisa de ninguna otra verificación o refrendo para su validez y plenos efectos procesales.

b) Los actos procesales que se realicen o tramiten con soporte informático, e inmediación virtualizada, requieren de la identificación previa de todos los actuantes y preservarán la confidencialidad, privacidad y seguridad de los datos de carácter personal (art. 230.4 LOPJ)

c) La exigencia de compatibilidad de sistemas entre actuantes y Administración de Justicia en los entornos de inmediación virtual en que se desarrollen actos procesales de forma telemática y el pleno respeto a las garantías y requisitos previstos en cada procedimiento (legalidad procesal), con una previsión de posible obligatoriedad en el uso de medios técnicos de telecomunicación con juzgados y tribunales para las "personas que demanden la tutela judicial de sus derechos e intereses ... cuando así se establezca en las normas procesales” (art. 230.5 LOPJ)

En relación con esta última precisión, conviene destacar la posición del Tribunal Constitucional, en cuya Sentencia 6/2019, de 17 de enero, dispone (Fundamento Jurídico Cuarto) que "la utilización de medios electrónicos para la práctica de actos de comunicación, desde el punto de vista de los sujetos que han de hacer uso de ellos puede configurarse como un derecho o bien como una obligación". En el primer caso (se trata de un derecho) se encuentran las personas físicas que actúan como parte en un proceso, sin requerir de un representante procesal -procurador- por no exigirlo la ley procesal. Establece, por el contrario, que se entiende como obligación relacionarse con la Administración de Justicia por canales electrónicos para los profesionales de la Justicia que intervienen en representación de alguna de las partes del proceso -Abogado y Procurador- cuando estas sean particulares, Administraciones territoriales, órganos parlamentarios o entidades de derecho público.

\subsection{Elementos para la virtualización en el proceso desde el principio de inmediación}

La voluntad legal de impulso tecnológico en el proceso, el previo aval constitucional a la realización de actuaciones telemáticas y una dotación esperable e imprescindible de medios es el triunvirato que sustenta la evolución contemporánea de la justicia, a lo que se suma un elemento extrajurídico como es la pandemia ocasionada por el Covid-19 que ha hecho del distanciamiento social, entre otras, una de sus consecuencias fundamentales como elemento de prevención. Una justicia telemática, y no solo de base procesal -que sobre ello proseguiremos en posteriores apartados del trabajo-, es imprescindible desde la implementación de soluciones tecnológicas para garantizar la adecuada tutela de los derechos e intereses de los ciudadanos. La apertura de la Justicia a una concepción extensa en la que también se incardinan medios extrajudiciales de resolución de litigios, cierra el círculo sobre el cual puede establecerse el 
ámbito de aplicación de la misma en las próximas décadas desde los factores de virtualización y extrajurisdiccionalidad.

En una perspectiva acotada al ámbito del proceso, en este punto del trabajo hemos de reiterar el aporte de agilidad, rapidez e inmediatez que comporta la virtualización de actuaciones procesales desarrolladas a través de herramientas de apoyo y soporte tecnológico. Pero ese progreso procedimental no puede tener lugar a cualquier precio, y menos si es a costa de una merma de garantías y derechos de los justiciables. Las actuaciones telemáticas en general, y en particular lo que de ellas repercute en el principio de inmediación ${ }^{32}$ en su vertiente virtualizada, deben atenerse ineludiblemente a una serie de requisitos y condiciones, como afianzamiento de su validez y de la exclusión de cualquier atisbo de nulidad.

Tomando las referencias legales de los arts. 229.3 LOPJ, con carácter general, y del art. 731 bis LECrim, desde el entorno procesal penal, podemos extrapolar una serie de elementos para la virtualización del principio de inmediación que verifican a priori la validez de los actos procesales conducidos desde una justicia digital y telemática. Seguidamente los enumeramos:

1) El acto procesal desarrollado telemáticamente ha de soportase desde un entorno digital seguro y que proteja adecuadamente los datos personales y la intimidad de los intervinientes

2) El acto procesal debe producirse de manera bidireccional (emisor del acto y receptor o receptores) y simultánea (sincrónica en el tiempo y con emisión en directo) de imagen y sonido.

3) Debe permitir la interacción visual, auditiva y verbal de todos los participantes, salvo que el órgano jurisdiccional, motivadamente, determine alguna concreta restricción -para la protección de los derechos o las garantías de alguno de los participantes en el acto-.

4) El acto procesal telemático debe llevarse a cabo desde la plenitud del principio de contradicción y el ejercicio del derecho de defensa, así como del resto de derechos procesales fundamentales

5) Observancia de todas las exigencias procedimentales establecidas en la ley procesal aplicable, para la versión presencial del acto siempre que sean posibles y adecuadas al entorno telemático en que se desarrolla

6) Intervención del Letrado de la Administración de Justicia para verificar la realidad, integridad y documentación -en soporte digital- del acto celebrado. Acreditará la identidad de los intervinientes por el medio que proceda (documentación acreditativa, como puede ser la exhibición del DNI o su previa remisión, firma digital, conocimiento personal u otro medio que se considere apropiado).

Extraemos entonces la conclusión de que el principio de inmediación va a verse matizado, y actualizado, en el entorno de una justicia digital y telemática, sin perder su esencia y sentido de ser originario. Esto es, el contacto entre juzgador y elementos del acto procesal será directo, pero ahora interpuesto a través de un mecanismo de nueva tecnología que sustituye la presencia física por una presencia e interacción virtual. En su Sentencia 161/2015 de 17 de marzo, el

\footnotetext{
${ }^{32}$ CABEZUDO RODRÍGUEZ, N., Del principio de inmediación, sus excepciones y los instrumentos tecnológicos. ed. Tirant lo Blanch, Valencia, 2010.
} 
Tribunal Supremo ${ }^{33}$ determinaba, en relación con la videoconferencia, que "el ritmo al que se suceden los avances tecnológicos obliga a no descartar que en un futuro no muy lejano la opción entre el examen presencial de los testigos/peritos y su interrogatorio mediante videoconferencia, sea una cuestión que no se plantee en términos de principalidad y subsidiariedad". Además, entendemos que se puede avanzar en incardinar en este nuevo entorno tecnológico de aplicación a la oralidad y la inmediación en su punto exacto de principios procedimentales que tratan, en cualquier caso, de facilitar la averiguación de los hechos en el proceso ${ }^{34}$. Pues bien, ese futuro, parece haber llegado ya, quizá azuzado por las consecuencias del Covid-19, y con el actual estado de cosas, el que denominaba el Tribunal Supremo, en la citada sentencia, "entendimiento histórico-convencional del principio de inmediación" sigue siendo considerado un valor que preservar pero que avanza en consonancia con las nuevas formas y opciones de actuación procesal que hacen prevalecer a la proximidad física y personal otros pormenores y singularidades. Y este fenómeno de digitalización, apuesta telemática e inmediación virtualizada -hasta el extremo de aplicar incluso inteligencias artificiales- veremos, seguidamente como ya ha hecho camino y abierto brecha en el ámbito de las soluciones extrajudiciales de litigios, quizá por su carácter más global, universal, informal y flexible que el proceso judicial.

Solo queda valorar, finalmente, con el posible riesgo de hacer depender determinadas actuaciones de la tecnología, cuando nos encontramos con carencias en las dotaciones materiales y con problemas de conectividad y funcionamiento en muchos juzgados o para alguno de los intervinientes cuya presencia sea imprescindible. Las incidencias derivadas de estas vicisitudes pueden repercutir negativamente, al tener que aplazar la realización del acto y con ello dilatar el procedimiento o en caso de que el acto desarrollado telemáticamente no haya tenido la calidad de audio o vídeo deseable y se haya podido recoger íntegro, puede llegar a comprometer su validez. En cualquier caso, y tal y como señaló de forma taxativa CORTÉS DOMÍNGUEZ ${ }^{35}$, quien sitúa a la inmediación en la esencia misma del proceso, como valor ${ }^{36}$ procesal por sí misma y cuya valoración no ha de depender de apreciaciones más o menos sociológicas sobre su eficacia o sobre si es más conveniente o imprescindible el contacto directo entre el órgano jurisdiccional y el acto procesal sino que "el enraizamiento claramente constitucional de la inmediación hace indiscutible la necesidad de la misma con independencia

\footnotetext{
${ }^{33}$ Referencia Roj: STS 812/2015 - ECLI: ES:TS:2015:812.

${ }^{34}$ LETELIER LOYOLA, E., “Oralidad, inmediación y la determinación de las verdades en el proceso penal”, Estudios actuales en Derecho y Ciencia Política, (Coord. Carrizo González-Castell, A.), ed. Andavira, Santiago de Compostela, 2011, pp. 3-31.

${ }^{35}$ CORTÉS DOMÍNGUEZ, V., "La Constitución española y los principios rectores del proceso civil”, Principios Constitucionales en el proceso civil. Cuadernos de Derecho Judicial núm., XXII, Madrid, 1993, pp. 139-140.

36 ANDRÉS IBÁÑEZ, P., "Sobre el valor de la inmediación (Una aproximación crítica)", en Jueces para la democracia, núm., 46, 2003, pp. 57-66.
} 
de si actuaciones procesales sin inmediación suponen o no un ataque o violación al derecho de defensa".

\section{4. ¿TECNOLÓGICAMENTE SON MÁS ÁGILES Y VENTAJOSAS LAS SOLUCIONES EXTRAJUDICIALES DE LITIGIOS?}

Uno de los fenómenos que está caracterizando la Justicia de las primeras décadas del siglo XXI es, incuestionablemente, la expansión de las soluciones extrajudiciales de litigios como elemento complementario a la solución de litigios en sede judicial. El modelo social que nos acoge propugna, cada día más, la libertad y la disponibilidad individual de los sujetos en prácticamente todas y cada una de las parcelas de su existencia. Esa autonomía también se observa en la gestión de sus derechos y obligaciones, vinculada al tradicional principio de autonomía de la voluntad, ciertamente, allí donde éste es posible jurídicamente hablando.

Sumamos a esta circunstancia el hecho, también fácilmente contrastable, de que los medios extrajudiciales de resolución de litigios son más universales y flexibles que el proceso judicial. Esta reflexión nos conduce a valorar como en un mundo cada día más globalizado, con litigios que incorporan con frecuencia elementos transnacionales ${ }^{37}$, soluciones que no se vinculan a un territorio y a unos patrones legales muy estrictos, como es el proceso judicial, pueden ir ganando terreno y posiciones para la asunción de determinados conflictos. El arbitraje, la mediación o una simple negociación, se mueven en parámetros menos marcados y aportan mayor flexibilidad en su utilización y resultados, lo cual casa perfectamente, de nuevo, con la premisa expuesta en el párrafo anterior, de la disponibilidad por parte del ciudadano de sus derechos, llegando al punto de disponer de la solución a los conflictos que de los mismos se desprendan.

La actual situación que vivimos, a nivel social y de relación e interacción, con la distancia social como regla básica, es un tercer elemento a considerar. Nos explicamos. En el ámbito de aplicación de los medios extrajudiciales de resolución de litigios no se requiere, en primer término, una interacción tan continuada y constante como en el proceso judicial. Además, los medios extrajudiciales se han adelantado al proceso judicial en la incorporación de nuevas tecnologías a su práctica habitual. Sirva de ejemplo la Plataforma Europea de resolución extrajudicial de litigios en línea en materia de consumo, impulsada institucionalmente desde la propia Unión Europea, y que lleva ya varios años en funcionamiento. Esta plataforma ha demostrado, desde los datos que ya disponemos sobre la misma, que es posible acceder a una solución extrajudicial de un litigio de forma totalmente telemática. La Plataforma electrónica europea de resolución extrajudicial de litigios de consumo es probablemente el señuelo de un modelo tecnológico y extrajudicial de justicia que puede extenderse, en un primer momento al

\footnotetext{
${ }^{37}$ A título de ejemplo podemos cierta un sector en que dada su transnacionalidad puede resultar muy ventajoso el uso de la mediación electrónica como es el caso de la litigiosidad marítima. Consúltese FONTESTAD PORTALÉS, L., "En busca de nuevas soluciones procesales y extraprocesales en el transporte marítimo de mercancías”, Revista de Derecho del Transporte, núm. 26, 2020.
} 
derecho privado, y posteriormente, a otros ámbitos jurídicos. Desde la conjunción de estos dos elementos, y con las circunstancias que actualmente tiñen de aislamiento y distancia nuestras relaciones interpersonales, se pueden asentar las bases de una justicia moderna y eficaz en las próximas décadas. Estas opciones también son justicia, y no solo en el ámbito del consumo ${ }^{38}$, a la que se accede evitando los riesgos que la pandemia del Covid-19 pudiera representar.

La sobrecarga de asuntos que han padecido los órganos jurisdiccionales, acentuada con las consecuencias de la pandemia del Covid-19 y las semanas de restricciones y de dificultades en el desempeño de la función jurisdiccional, pueden encontrar un perfecto aliado para la descongestión y para potenciar la eficacia de la Justicia en la tecnología y en las vías extrajurisdiccionales de resolución de litigios, estando éstas más preparadas y avanzadas para dar respuesta a muchos tipos de conflictos desde dispositivos digitales de acceso universal (ordenadores, portátiles, teléfonos inteligentes, tabletas, etc) en los cuales llevar a cabo de forma flexible y directa un arbitraje, una mediación, una conciliación o una negociación. Estaríamos con ello invirtiendo también el esquema tradicional basado en que ha de ir a buscarse la justicia a una concreta sede física -los juzgados y tribunales-, cuando desde la comodidad y cercanía del hogar o el lugar de trabajo se podría avanzar en la resolución de un conflicto con todas las garantías jurídicas. Además, esto comportaría ventajas en cuanto a la agilidad, rapidez, manejabilidad o disminución de gastos que determina la necesidad de acudir a un proceso judicial. Tal vez se propicie también una mayor satisfacción a los justiciables, quienes asumen responsabilidad y protagonismo al encarar el conflicto que afecta a sus derechos o expectativas. La moderna faz de la Justicia sería poliédrica, con varias caras en las cuales el justiciable puede acomodar su litigio.

\footnotetext{
${ }^{38}$ Así, por ejemplo, en enero de 2018, se ha dado a conocer la implementación en España de una plataforma de tramitación electrónica de resolución extrajudicial de conflictos derivados de accidentes de tráfico en relación a las reclamaciones de daños personales a las aseguradoras. De este modo, y en virtud de un convenio suscrito al efecto entre el Consejo General de la Abogacía y la Patronal de las Aseguradoras (UNESPA), se ha desarrollado una plataforma electrónica (a través de la empresa TIREA) que permite a los letrados comunicarse de forma telemática y segura con las aseguradoras de los vehículos que se han visto implicados en un siniestro de circulación con víctimas facilitando la solución extrajudicial del litigio. A dicho Convenio se han adherido en la actualidad un total de 23 aseguradoras -que representan el 90\% del mercado en España-. El nuevo servicio se llama SdP-Lex. Mediante dicha herramienta online, los abogados envían y reciben de manera segura, inmediata y estandarizada la documentación con las reclamaciones de sus clientes a las entidades aseguradoras. El trasvase de información se realiza a través de la firma electrónica cualificada de la Autoridad de Certificación de la Abogacía (ACA). La plataforma posibilita el diálogo entre el abogado y la entidad en base a lo establecido en el convenio suscrito la pasada primavera entre el Consejo General de la Abogacía Española, UNESPA y TIREA. Otra ventaja de SdPLex es que es un servicio operativo todos los días del año y a todas horas. El sistema cumple, igualmente, los criterios establecidos por las normas de competencia y protección de datos.
} 


\section{MEDIOS EXTRAJUDICIALES DE RESOLUCIÓN DE LITIGIOS, TECNOLOGÍA E INTELIGENCIA ARTIFICIAL: EL RETO DEL PRESENTE}

Las $\mathrm{ODR}^{39}$, acrónimo anglosajón con el que se designan a los medios extrajudiciales de resolución de litigios online, y por tanto con aplicación directa de la tecnología y de soluciones fundamentalmente telemáticas, serán un elemento de referencia en la justicia post-covid19. El confinamiento y las restricciones de movilidad y de contacto personal han expandido y convertido en cotidiano el uso y acceso a dispositivos de nuevas tecnologías para llevar a cabo a través de ellos, muchas de las actividades que anteriormente hacíamos presencialmente, con inmediación. Se han derribado muchas barreras en este sentido, pese a las divergencias y dificultades que para muchos colectivos supone el empleo de nuevas tecnologías. Llegados a este punto, el ámbito de la justicia no puede, ni debe, quedar atrás, y debe aprovechar el viento a favor. Y para ello están, indudablemente, mucho mejor posicionados los medios extrajudiciales de resolución de litigios que se conducen online. Dotarlas, además, de transparencia y al mismo tiempo de confidencialidad y adecuada protección de datos reforzará su idoneidad ${ }^{40}$.

El convencimiento de que la innovación constante, la oferta de alternativas al proceso y las capacidades de los profesionales jurídicos en adaptarse a nuevas realidades para orientar y asistir a los ciudadanos en su obtención de soluciones a sus litigios son los parámetros que pueden conducirnos a una mayor eficiencia y un mejor acceso a la Justicia. A todos ellos se suma un protagonista estelar: la inteligencia artificial y su irrupción a todos los niveles y en el mundo de la Justicia en particular ${ }^{41}$.

\section{1. ¿Qué es inteligencia artificial en el ámbito jurídico?}

El primer recurso conceptual sobre inteligencia artificial entendemos que debe ser generalista y para ello acudimos a la Real Academia Española, que la define como la "especialidad científica que genera programas informáticos, que se encargan de realizar un trabajo similar al

\footnotetext{
${ }^{39}$ KAUFMANN-KOHLER, G., y SCHULTZ, T., Online Dispute Resolution: Challenges for Contemporary Justice, Kluwer Law International, 2004.

${ }^{40}$ RULE, C., HARPREET SINGH, H., "ODR and Online Reputation Systems - Maintaining Trust and Accuracy Through Effective Redress”. Online Dispute Resolution: Theory \& Practice. A teatrise on technology and dispute resolution, (coord.. Abdel Wahab,M. S., Katsh. E., Rainey, Eleven, D.), 2011, pp. 175-196.

${ }^{41}$ Según MIRÓ LLINARES la transformación que en la justicia puede acarrear la entrada de la inteligencia artificial "suele conllevar respuestas iniciales dicotomizadas entre, por un lado, el temor y la negación del cambio $\mathrm{y}$, por otro, la esperanza y la aceptación del mismo sin ambages", vid., MIRÓ LLINARES, F. "Inteligencia Artificial y Justicia Penal: más allá de los resultados lesivos causados por robots", Revista de Derecho Penal y Criminología, 3(20), 2018, p. 110.
} 
que ejecuta la mente del ser humano, como podría ser el aprendizaje o el razonamiento lógico ${ }^{42}$ ".

Probablemente la definición que más nos puede ir aproximando, ya de forma técnica, a la consideración de la inteligencia artificial nos la ofrece la Comunicación de la Comisión al Parlamento Europeo, el Consejo Europeo, el Comité Económico y Social Europeo y el Comité de las Regiones sobre Inteligencia Artificial para Europa (referencia: COM (2018) 237 final) según la cual por inteligencia artificial podemos entender los sistemas que muestran un comportamiento inteligente al analizar su entorno y realizar acciones, con cierto grado de autonomía, para lograr objetivos específicos. Si la completamos con lo expuesto en las "Directrices éticas para una inteligencia artificial confiable" preparadas por el Grupo de expertos de alto nivel sobre inteligencia artificial (AI HLEG) de la Unión Europea, donde apunta que se trata de "sistemas de software (y posiblemente también hardware) diseñados por seres humanos que, dado un objetivo complejo, actúan en la dimensión física o digital al percibir su entorno a través de la adquisición de datos, interpretando los datos recopilados o no estructurados, razonando sobre el conocimiento, o el procesamiento de la información, derivado de estos datos y la decisión de las mejores acciones a tomar para lograr el objetivo dado".

La aplicación de inteligencia artificial en el derecho ${ }^{43}$ se conoce, siguiendo una vez más la terminología anglosajona, como Artificial Legal Intelligence (bajo el acrónimo ALI) y está basada en el desarrollo de la automatización de razonamientos jurídicos y en su aplicación en modelos computacionales de argumentación jurídica. Podemos llegar a concluir, por tanto, que la inteligencia artificial en el ámbito jurídico implica un elemento tecnológico capaz de brindar apoyo para asesorar legalmente, asistir en la toma de decisiones e incluso, en sus versiones más avanzadas, asumir la responsabilidad de la decisión de un litigio en ámbitos procesales ${ }^{44}$ y extrajurisdiccionales.

\subsection{El desafío de incorporar la inteligencia artificial en los entornos de ODR}

La necesidad perentoria de sumar nuevos factores emergentes que hagan evolucionar la justicia post-covid19, tiene uno de sus escenarios más idóneos en la adaptación de los entornos ODR ${ }^{45}$, caracterizados por la utilización de la tecnología y la telemática y por tanto sin contacto directo.

\footnotetext{
42 Real Academia Española, Diccionario de la lengua española, (versión 23.3 disponible en la web https://dle.rae.es).

${ }^{43}$ SURDEN, H., “Artificial intelligence and Law: an overview”, Georgia State University Law Review, vol. 35, núm., 4, 2019, pp. 1305-1337.

${ }^{44}$ NIEVA FENOLL, J., Inteligencia artificial y proceso judicial, Marcial Pons, Madrid, 2018.

${ }^{45}$ SOLETO MUÑOZ, H., “Avances, tecnología y ADR en el sistema de justicia. La necesaria revolución de los sistemas de resolución de conflictos”, La Justicia digital en España y la Unión Europea, (dirs. Conde Fuentes, J., y Serrano Hoyo, G.), Barcelona, 2019, pp. 341-353.
} 
En este sentido, el punto de partida es ideal. Si al arbitraje ${ }^{46}$, o la mediación electrónica le activamos un elemento disruptivo como la inteligencia artificial, el desafío de las soluciones extrajudiciales de litigios online, las transformará de ODR en i-ODR (entendido como el acrónimo que englobaría la utilización de sistemas de ODR con asistencia de inteligencia artificial).

En estos términos considero que se plantea el desafío de una Administración de Justicia que evolucione como consecuencia de la crisis que ha producido la pandemia del covid-19. Una Administración de Justicia de visión amplia, integradora y que debe apostar firmemente por un modelo tecnológico de vanguardia. Dar cabida dentro de ella a los ODR y los posibles i-ODR ${ }^{47}$ confirmaría una decida apuesta por la agilidad, la eficiencia y la ubicuidad temporal y espacial de las vías extrajudiciales de resolución de litigios como complemento eficaz al proceso judicial, en sintonía con el tiempo en que vivimos y con las aplicaciones de inteligencia artificial y el procesamiento de big data, algoritmos, etc que deriven en el diseño final de softwares aplicados a arbitraje y mediación online que desempeñen funciones tanto de asistencia (pasiva) como decisoria (activa) en la resolución de litigios. Nuestras observaciones se dirigen, entonces, hacia la vinculación entre inteligencia $\operatorname{artificial}^{48}$ y mecanismos extrajudiciales de resolución de litigios en línea (ODR) sobre un sustrato común que les confiera plena operatividad, interconexión y regularidad legal. Ambas opciones, ODR e IA, comparten su naturaleza de base tecnológica, pero por ello no deben, ni pueden, quedar fuera de las exigencias jurídicas de garantismo que cualquier procedimiento de resolución de litigios requiere, ya sea judicial o extrajudicial. En particular, las ODR deben observar las mismas normas y principios generales que sus réplicas en versión presencial (o fuera de línea), tanto con relación a los derechos de las partes en litigio y a los derechos y obligaciones del tercero neutral (árbitro o mediador) como a las exigencias procedimentales básicas.

\subsection{A. Inteligencia artificial con funciones asistenciales en entornos ODR}

A buen seguro que la inteligencia artificial puede ser un elemento de apoyo en el desarrollo de un arbitraje o una mediación electrónica. La gama de soluciones que puede brindar se extiende

\footnotetext{
${ }^{46}$ BARONA VILAR, S. "Maximización de la eficiencia y búsqueda de la celeridad en el arbitraje: entre el mito, la sublimación y la cuarta revolución industrial (4.0)", Revista de Arbitraje Comercial e Inversiones, núm. 1, vol. XI, 2018, pp. 17-53; MATHEUS LÓPEZ, C. "Tecnología y arbitraje internacional en tiempos del coronavirus", CIAR Global, accesible en el vínculo: https://ciarglobal.com/tecnologia-y-arbitraje-internacional-en-tiempos-delcoronavirus/.

47 MARTÍN DIZ, F., Inteligencia artificial y medios extrajudiciales de resolución de litigios online (ODR): evolución de futuro en tiempos de pandemia global (COVID-19), Revista La Ley. Mediación y Arbitraje, núm. 2 , 2020, pp. 48-93.

${ }^{48}$ Véase White Paper on artificial intelligence - an European approach to excellence and trust desde donde se aboga por su implementación, desarrollo y empleo respetando los principios y valores fundamentales de la Unión Europea. En el ámbito jurídico desde la observancia plena de los derechos fundamentales de la ciudadanía.

https://ec.europa.eu/info/sites/info/files/commission-white-paper-artificial-intelligence-feb2020_en.pdf,
} 
desde la designación del tercero que participa junto a las partes en la resolución del litigio, hasta el manejo de los datos y predicciones que puedan ser de ayuda y orientación en alguna de las decisiones o actuaciones que deban desenvolver en su labor $\operatorname{arbitral}^{49}$ o mediadora $^{50}$. Con el grado de implantación y utilización que la inteligencia artificial presenta hoy en día en este ámbito, probablemente es el que está mas cerca de sus posibilidades reales y legales por cuanto aún parece muy aventurado, y con límites aún desconocidos, el conceder a la inteligencia artificial la capacidad decisoria en arbitrajes o mediaciones electrónicas -lo que no significa que ya haya casos en que se está haciendo-. Nos postulamos defensores, al menos por ahora, del principio human in command por el cual se proclama que la máquina es controlada por el ser humano y éste fortalece su aplicación, es el núcleo desde el cual debiera expandirse la utilización de la inteligencia artificial ${ }^{51}$.

La evolución tecnológica nos puede llevar, por tanto, a que una inteligencia artificial sea útil para evaluar la conveniencia de un arbitraje $\mathrm{e}^{52}$ o una mediación, e incluso de su variante telemática, aportando tendencias y ventajas en cuanto a tiempo, coste y soluciones de un litigio frente a su planteamiento jurisdiccional. En definitiva, una primera aplicación asistencial de la inteligencia artificial sería de carácter estratégico y pre-litigioso, para apoyar, fundamentar y ponderar la elección de la vía más idónea para la resolución del asunto. Puede ser igualmente un recurso de interés para los contendientes, sobremanera para sus asesores legales, a efectos de determinar una posible trazabilidad y orientación del caso en arbitraje y mediación, desde la elección de sus variantes (por ejemplo, en el caso del arbitraje determinar si conviene que sea de derecho o de equidad), o la elección de la modalidad entre arbitraje o mediación institucional (y en su caso, ante qué institución) o ad hoc (con posibles recomendaciones procedimentales adaptadas al asunto), etc. También sería un recurso válido para el procesamiento y análisis de datos, documentos y precedentes con los cuales los defensores legales de las partes pueden preparar sus alegatos y posiciones, y de otra parte los árbitros o mediadores pueden revisar las posiciones de las partes con mayor rapidez y agilidad, e, incluso, con la ventaja de que en el entorno tecnológico que propician las ODR la interactividad puede ser superior que la del entorno físico presencial.

\footnotetext{
49 MÉNDEZ ZAMORA, E., "Panorama actual y futuro de la inteligencia artificial en el arbitraje internacional: implementaciones, obstáculos y consideraciones jurídicas", Revista Costarricense de Derecho Internacional, núm., 1, 2018, pp. 6-24.

${ }^{50}$ BUENO DE MATA, F., "Mediación electrónica e inteligencia artificial”, Actualidad Civil, núm. 1, 2015.

51 En las citadas la Conclusiones del documento "Acceso a la Justicia: aprovechar las oportunidades de digitalización", referencia 2020/C342I/01, su apartado 39 subraya "que el uso de herramientas de inteligencia artificial no debe interferir con el poder de decisión de los jueces ni con la independencia judicial. Las resoluciones judiciales deben ser siempre dictadas por seres humanos y no pueden delegarse en una herramienta de inteligencia artificial".

52 PAISLEY, K., Y SUSSMAN, E., “Artificial Intelligence Challenges and Opportunities for International Arbitration”, NYSBA NY Dispute Resolution Lawyer, núm., 1, 2018, pp. 35-40.
} 
Podría ser aplicable la inteligencia artificial en este campo, como ya hemos señalado, para que sea esta herramienta tecnológica quien opere la selección y designación del árbitro ${ }^{53}$ o mediador (o de la institución, en caso de los modelos institucionales de ambos) desde unos criterios o recomendaciones que pautaran los litigantes y que tratarían con ello de conseguir la mayor objetividad posible para que se corrija la intuición y las referencias personales o profesionales por una recomendación soportada sobre datos como la especialidad del árbitro o mediador, sus tasas de actividad o sus propias habilidades y preferencias mostradas a través de cuestionarios que aporten información concreta, real y precisa del árbitro o mediador. Si esta circunstancia se abre paso, podría tener cabida su previsión legal, mediante la correspondiente modificación legislativa en los arts. 15 de la Ley de Arbitraje y 16.1.a) de la Ley de Mediación en asuntos civiles y mercantiles, como un ejercicio de adaptación a la realidad jurídico-social y tecnológica del momento, siempre que se haga dicha asistencia con las máximas garantías de transparencia y control por el usuario.

Finalmente, y en relación con la parte conclusiva de un procedimiento de ODR, sea un arbitraje o una mediación electrónica, una inteligencia artificial puede asistir a los árbitros o a los mediadores en la preparación, redacción y estructuración del contenido del laudo o acuerdo, especialmente en cuanto a comprobar de una parte que el laudo o acuerdo aborda todo el objeto del litigio y a garantizar su coherencia interna e incluso su regularidad legal.

\subsection{B. Un modelo de transición en ODR con aplicaciones de inteligencia artificial}

Existen ya en marcha experiencias en ODR en que, mediante negociaciones automatizadas en sede electrónica, se percibe una especie de modelo de transición entre la aplicación de inteligencia artificial a las ODR con funciones meramente asistenciales y las aplicaciones de inteligencia artificial en ODR a las que se otorgasen funciones decisorias. En estos modelos de interacción, el perfil negociador que se asigna a la inteligencia artificial es parecido al de un "asignador automático" que sitúa la resolución del conflicto en un término medio al que se llega desde los indicios y posturas ofrecidas por las partes. En nuestro caso tenemos incluso un precedente, ya algo remoto, con la previsión que en su momento contenía el Borrador del Real Decreto-ley que precedió a la vigente Ley de mediación en asuntos civiles y mercantiles contenía. El art. 16 del citado texto prelegislativo contemplaba una "especie" de mediación automatizada que, en atención a la naturaleza de ésta, constituía realmente una negociación automatizada electrónica. En la propuesta se preveía que, una vez recibidas las posiciones de las partes, si hubiera acuerdo sobre la cantidad reclamada, "el sistema electrónico les ofrecerá de forma automática una propuesta de acuerdo para su aceptación”. Si dicha propuesta se rechazase por alguna de las partes, ya fuese la mera propuesta económica o la propuesta de acuerdo final, ambas efectuadas por el sistema electrónico, "se podría solicitar al sistema una

\footnotetext{
${ }^{53}$ ROGERS, C.A., "Arbitrator Intelligence: From Intuition to Data in Arbitrator Appointments", New York Dispute Resolution Lawyer. Vol. 11, núm., 2, 2018.
} 
nueva propuesta con el límite de ofertas que establezcan las reglas de la institución de mediación". Con este planteamiento es evidente que una herramienta de inteligencia artificial podría asumir perfectamente ofrecer esta modalidad de negociación automatizada (una ODR, al fin y al cabo) ya que la previsión normativa de aquel entonces aludía a "sistemas electrónicos", sin precisar ni restringir qué entender por tales. Opción que es absolutamente factible en la actualidad en que los modelos computacionales para la creación de una inteligencia artificial son capaces de gestionar desde flujos de tráfico hasta complejas operaciones de trading en los mercados financieros. Dicho precepto, origen remoto del vigente art. 24.2 de la Ley 5/2012 de mediación en asuntos de derecho civil y mercantil, no pasó de ahí, de ser considerada en el Borrador de Real Decreto-ley, y no cuajó normativamente ni ha vuelto a ponerse sobre la mesa.

En la actualidad ya existen herramientas de ODR con inteligencia artificial implementada que realizan funciones de negociación asistida. Una de ellas es SmartSettle ${ }^{54}$, un software diseñado como una especie de "adjudicador" de controversias, basado en una negociación bilateral electrónica y mediante algoritmos. Ofrece un espacio telemático en el cual se reciben las posturas de las partes y se generan diferentes opciones de acuerdo, tomando como punto de partida las posiciones esgrimidas por cada uno de los afectados en el litigio. Funciona como un procedimiento electrónico, cooperativo, online y que requiere del acuerdo final de todos los implicados sobre la base de las opciones que va generando la interfaz interactiva. Otra de las herramientas de este tipo que también se ha implementado con similares características es Modria, como software inicialmente desarrollado para gestionar en Ebay ${ }^{55}$ y PayPal los millones de reclamaciones anuales de sus clientes de forma rápida y telemática. Dentro de sus variantes, cuenta con un "módulo de negociación" que resume las áreas de acuerdo y desacuerdo y hace sugerencias para resolver el problema.

\subsection{Inteligencia artificial decisoria en ODR: ¿i-arbitraje o i-mediación?}

El paso más arriesgado lo determina la valoración que implica vincular ODR e inteligencia artificial en funciones decisorias. Esto es, conferir a la herramienta tecnológica la facultad de decidir (arbitraje) o de mediar, sustituyendo con ello al humano que asume todas esas funciones legales y jurídicas en pleno ${ }^{56}$. Ese reemplazo puede llevarse a cabo ya sea en la forma de agentes relacionales ${ }^{57}$, robots, avatares, etc., diseñados y calibrados como solución tecnológica a estos

\footnotetext{
54 iCan Systems Inc. es el creador de Smartsettle, publicitado como "único sistema de negociación electrónica seguro del mundo que utiliza algoritmos de optimización patentados para lograr soluciones justas y eficientes que realmente están más allá de Win-Win”. Puede visitarse su web: https://www.smartsettle.com/

${ }^{55}$ KATSH, E., RIFKIN, J, GAITENBY, A., "E-Commerce, E-Disputes, and E-Dispute resolution: in the shadow of “eBay Law”, Ohio State Journal on Dispute Resolution, vol. 15:3, 2000, pp. 705-734.

${ }^{56}$ LARSON, D.A., “Artificial Intelligence: Robots, Avatars, and the Demise of the Human Mediator”, Ohio State Journal on Dispute Resolution, núm. 1, 2010, pp. 105-163.

${ }^{57}$ Como expone Larson, op.cit, p. 155, "Relational agents can contribute to dispute resolution and problem-solving processes both by behaving intelligently and being intelligent. Their ability to connect with humans by engaging,
} 
efectos y que, como ya avanza BARONA VILAR, en la sociedad global que tenemos a día de hoy no es más que una manifestación “desde parámetros de eficiencia que comportan cada vez más una superación del ser humano por la máquina..., quizá en el futuro, la inteligencia artificial supere el pensamiento humano crítico, sus imperfecciones, y sea capaz de equilibrar eficiencia con derechos. De momento, genera una cierta inquietud ese paso de la creación de las máquinas con pensamiento humano a la conformación de los humanoides, a saber, de crear máquinas que creen su propio pensamiento $\mathrm{y}$, por ende, su capacidad sui generis de resolver" 58 .

Hemos destacado la gran ventaja que comportan los medios extrajudiciales de resolución de litigios en cuanto a la flexibilidad de la que están imbuidos. Ello les permite adaptarse a la cambiante realidad social, y, ahora, ponerse en la vanguardia tecnológica mediante los ODR e incluso, como señalamos, su interacción con herramientas de inteligencia artificial. Dar un paso al frente para configurar sistemas extrajudiciales online de resolución de litigios con inteligencias artificiales decisorias, lo que podríamos catalogar como i-arbitraje o i-mediación, sería una confirmación de dicha flexibilidad. Cuando las tecnologías ya son parte indisoluble de nuestra vida diaria, cuando esta pandemia del año 2020 nos ha hecho tecnológicamente más dependientes ante el aislamiento y la restricción del contacto social, cuando las nuevas generaciones son nativas digitales, parece que el camino a seguir no puede ser otro.

Ahora bien, también puede aparecer barreras e inconvenientes. La primera objeción que se puede formular es de propiamente técnica, ya que actualmente nadie ni nada puede garantizar la infalibilidad y perfección total de un sistema de inteligencia artificial. Un sistema de inteligencia artificial puede tener defectos internos (defectuosa calibración o programación) o externos (mala conexión, ataque al sistema) lo cual nos llevaría a que no cumpla sus funciones de forma adecuada o apropiada. Tampoco la inteligencia artificial es sinónimo de eficacia absoluta y satisfacción total para los justiciables, que lo percibirán en función del resultado respecto a sus propios intereses. Además, hay que valorar la comodidad de los usuarios de un sistema de resolución extrajudicial de litigios online gestionado directa -y de forma única- por una inteligencia artificial. Puede, evidentemente, resultarles extraño y poco amigable, con lo que valorarían desistir del mismo y optar por sistemas con componente humano. Nos cuestionamos, igualmente, si las inteligencias artificiales diseñadas para estos propósitos tendrán capacidad de adaptación a cada concreto asunto, con sus matices, aristas y pretensiones de las partes, tanto en relación con la evolución de la posición de las partes a lo largo del procedimiento como con los cambios normativos y sociales que puedan tener vinculación con el asunto litigioso.

expressing emotion, collaborating, and creating social relationships can be quite valuable to a dispute resolution or problem solving process. Before a mediation session begins, for instance, parties may be anxious and unsettled. The chance to interact with an empathetic, conversational relational agent, infinitely patient and willing to review and repeat without any loss of attentiveness, may prove especially helpful".

${ }^{58}$ BARONA VILAR, S. "Maximización de la eficiencia...", op.cit, p. 24. 


\section{VALORACIÓN CONCLUSIVA}

La tecnología ha llegado al mundo de la Justicia no solo para quedarse, también para transformarla. Transformación que se produce en el ámbito del proceso y, de forma más significativa gracias a su flexibilidad, en el de los medios extrajudiciales de resolución de litigios, particularmente en aquellos encauzados electrónicamente. Indudablemente, la Justicia de las próximas décadas se nos antoja incluso impredecible en su estructura y funcionamiento, pero desde luego absolutamente conectada a realidades tecnológicas y telemáticas. No descuidemos un riesgo que se cierne sobre ella, pues es una justicia vulnerable por cuanto en cualquier entramado electrónico, hasta en los más protegidos, el intrusismo, el acceso a los datos y las vulnerabilidades del sistema también han de ser consideradas y especialmente protegidas. Las medidas de protección que se adopten en este sentido serán también elemento crucial en la justicia virtualizada que se presenta a las puertas de los próximos años.

¿Encontraremos en el futuro jueces ${ }^{59}$, árbitros o mediadores virtuales que hayan sustituido a humanos? Desde luego el desarrollo tecnológico lo hará posible, cuestión distinta es que social, humana y legalmente sea aceptable y conveniente. Más plausible parece, a primera vista, en el entorno de los medios extrajudiciales de resolución de litigios conducidos en sedes electrónicas. Aún así, en este sentido me parecen ilustrativas las reflexiones de $\mathrm{SIM}^{60}$ en relación con los procesos humanos que conducen a la decisión y el componente subjetivo que está detrás de la labor del árbitro -decidiendo- o del mediador -asistiendo o facilitando-, al considerar que es casi imposible de trasladar a una inteligencia artificial, aún incluso, así se nos antoja, cuando árbitros o mediadores participen activamente junto a ingenieros informáticos en el diseño de la inteligencia artificial. Apostar por una inteligencia artificial que asuma funciones decisorias en la resolución de litigios, sea en el modelo y opción que sea, exige un alto perfeccionamiento de lo que se conoce como "programas de verificación de diversidad" que comprueban su correcto calibrado para que esta no cree tendencias sesgadas, discriminatorias, desproporcionadas en relación con los datos reales y objetivos, partiendo para ello del manejo de grandes conjuntos de datos previamente aplicados para evaluar la diversidad de sesgos.

La Justicia está presidida por el garantismo, encarnado básicamente en el respeto a una serie de principios y derechos fundamentales. Esto exigirá que las herramientas de inteligencia artificial sepan conjugar adecuadamente la flexibilidad procedimental propia de las resoluciones extrajudiciales de litigios online con las debidas garantías procedimentales que han de observarse en todo caso. A día de hoy, uno de los motivos por los que pese a todos sus defectos,

\footnotetext{
${ }^{59}$ DE TRAZEGNIES, F., “¿Seguirán existiendo jueces en el futuro? El razonamiento judicial y la inteligencia artificial”, Revista Ius et Veritas, núm., 47, 2013, pp. 112-130.

${ }^{60}$ SIM, C., "Will Artificial Intelligence Take Over Arbitration?”, Asian International Arbitration Journal, núm., 1, 2018. Puede consultarse en:

https://www.academia.edu/36646259/Will_Artificial_Intelligence_Take_Over_Arbitrators_2018_forthcoming_ Asian_Journal_of_International_Arbitration
} 
acudimos a la justicia procesal viene dado por que existe un sistema estructurado de justicia que ante una vulneración de las garantías (fundamentalmente a través del sistema de recursos) promueve su subsanación, además de que toda resolución judicial al estar motivada permite conocer los entresijos de la misma, cuestión que frente al secreto del algoritmo de una inteligencia artificial (la denominada caja negra o black box) que mantiene a ultranza su creador bajo el halo de la protección de los derechos de propiedad industrial o la patente de la misma, se nos antoja harto complicada de ponderar y, posteriormente, de enmendar por cuanto no existe un sistema, como tal, de revisión de resoluciones arbitrales (salvo en el caso interno el recurso de anulación del laudo) o de impugnación de acuerdos de mediación (salvo su anulabilidad) en parangón con la previsión de los sistemas de impugnación en el ámbito jurisdiccional.

La tecnología aportará innegables ventajas, pero disminuirá el factor humano y el humanismo en el derecho y en el ámbito de la Justicia. Actos interpuestos, sin inmediación presencial, más ahora con la pandemia que nos asola y los impide o condiciona por razones sanitarias y de distanciamiento social, que no ofrecen el mismo contacto inmediato y directo que la cercanía personal. Es indudable pero también parece irremediable por razones aquí expuestas. Más acuciante aún con el crecimiento de la dependencia de la inteligencia artificial como recurso tecnológico para todo y que nos llevará, a no mucho tardar, a conocer i-árbitros e i-mediadores con forma de robot, avatar o similar.

Pero no debemos olvidar que el derecho, la justicia y la resolución de litigios es una creación y una actividad humana, por encima de todo y que debe estar siempre bajo su supervisión y control. Es por ello por lo que una expresión de este control humano, del predominio del humanismo sobre la tecnología en materia de ODR y con la irrupción de la inteligencia artificial $^{61}$, debe ser el derecho irrenunciable de los ciudadanos, como usuarios tecnológicos, a objetar de su utilización. Cualquiera de las partes en un litigio resuelto en arbitraje o mediación electrónica tiene la facultad, libre, voluntaria e incondicional, de rechazar la utilización de un agente relacional o de un software, como inteligencia artificial, sea en funciones asistenciales, sea en funciones decisorias.

Hacer predicciones a futuro es una quimera que se vence por el tiempo con fugacidad ante escenarios inesperados. La pandemia que ha producido la aparición del virus Covid-19 es una dolorosa muestra de ello. Con la experiencia y resultados de los meses que ya hemos vivido inmersos en esta singular y exigente situación quizá podamos extraer algunas conclusiones para la justicia postpandemia. Una es que la potenciación de los recursos telemáticos en la justicia, procesal y extrajudicial, será irrebatible. La otra es que tal vez estemos ante la eclosión definitiva de los medios extrajudiciales de resolución de litigios en línea y, en una versión más avanzada y aún por definir, ante la implementación de soluciones de inteligencia artificial en

\footnotetext{
${ }^{61}$ BARONA VILAR, S., "Psicoanálisis de las ADR. Retos en la sociedad global del siglo XXI", La Ley. Mediación y Arbitraje, núm., 1, 2020, pp. 51-54.
} 
los ODR que lleguen hasta el extremo de brindarnos figuras quizá hoy inimaginables como el i-árbitro o el i-mediador. Todo lo anterior, con o sin pandemia, con o sin justicia post-pandemia, siempre desde el respeto en el ámbito de la Justicia a su esencia: los derechos fundamentales ${ }^{62}$ de las personas y el control humano de cualquier recurso tecnológico para hacer Justicia y resolver litigios.

\section{RELACIÓN BIBLIOGRÁFICA}

ANDRÉS IBÁÑEZ, P., "Sobre el valor de la inmediación (Una aproximación crítica)”, en Jueces para la democracia, núm., 46, 2003

BARONA VILAR, S. “Maximización de la eficiencia y búsqueda de la celeridad en el arbitraje: entre el mito, la sublimación y la cuarta revolución industrial (4.0)", Revista de Arbitraje Comercial e Inversiones, núm. 1, Vol. XI, 2018

BARONA VILAR, S., "Psicoanálisis de las ADR. Retos en la sociedad global del siglo XXI", La Ley. Mediación y Arbitraje, núm., 1, 2020

BUENO DE MATA, F., "E-Justicia: hacia una nueva forma de entender la justicia", Revista Internacional de Estudios de Derecho Procesal y Arbitraje, núm., 1, 2010

BUENO DE MATA, F., "El uso de la videoconferencia en el proceso penal: ¿existencia de la inmediación virtual?, Estudios actuales en Derecho y Ciencia Política, Coord. A. Carrizo González-Castell, Ed. Andavira, Santiago de Compostela, 2011

BUENO DE MATA, F., "Mediación electrónica e inteligencia artificial", Actualidad Civil, núm. 1, 2015

CABEZUDO BAJO, M.J., "Avance hacia un juicio penal íntegramente telemático mediante un uso más generalizado de la videoconferencia: eficiencia y derechos fundamentales", Revista General de Derecho Procesal, núm., 52, 2020

CABEZUDO RODRÍGUEZ, N., "Aproximación a la teoría general sobre el principio de inmediación procesal. De la comprensión de su trascendencia a la expansión del concepto", Oralidad y escritura en un proceso civil eficiente, edits. F. Carpi y M. Ortells Ramos, vol. 2, Valencia, 2008

\footnotetext{
${ }^{62}$ MARTÍN DIZ, F., "Inteligencia artificial y proceso: garantías frente a eficiencia en el entorno de los derechos procesales fundamentales”, Justicia: ¿garantías versus eficiencia?, (dir. Bellido Penadés. R.), 2019, pp. 815-827; COTINO HUESO, L., "Big data e inteligencia artificial. Una aproximación a su tratamiento jurídico desde los derechos fundamentales", Revista DILEMATA, 24, 2017, pp. 131-150 y "La necesaria actualización de los derechos fundamentales como derechos digitales ante el desarrollo de internet y las nuevas tecnologías", España constitucional (1978-2018): trayectorias y perspectivas, (dir. Pendás García, B.), vol. 3, tomo 3, 2018, pp. 23472361.
} 
CABEZUDO RODRÍGUEZ, N., Del principio de inmediación, sus excepciones y los instrumentos tecnológicos. Ed. Tirant lo Blanch, Valencia, 2010

CHIOVENDA, G., Ensayos de Derecho Procesal Civil, Buenos Aires, 1949

CORTÉS ABAD, O., "Justicia digital, abierta e innovadora. Hechos y retos", Modernización digital e innovación en la Administración de Justicia, Coord. M.F. Gómez Manresa y M. Fernández Salmerón, Ed. Thomson Reuters Aranzadi, Cizur Menor, 2019.

CORTÉS DOMÍNGUEZ, V., "La Constitución española y los principios rectores del proceso civil”, Principios Constitucionales en el proceso civil. Cuadernos de Derecho Judicial núm., XXII, Madrid, 1993

COTINO HUESO, L., "Big data e inteligencia artificial. Una aproximación a su tratamiento jurídico desde los derechos fundamentales", Revista DILEMATA, 24, 2017

COTINO HUESO, L., "La necesaria actualización de los derechos fundamentales como derechos digitales ante el desarrollo de internet y las nuevas tecnologías", España constitucional (1978-2018): trayectorias y perspectivas, Pendás García, B. (dir.), vol. 3, tomo 3, 2018

DE TRAZEGNIES, F., “Seguirán existiendo jueces en el futuro? El razonamiento judicial y la inteligencia artificial”, Revista Ius et Veritas, núm., 47, 2013

DEL POZO PÉREZ, M., "La quiebra de la inmediación en la segunda instancia del proceso civil", Oralidad y escritura en un proceso civil eficiente, edits. F. Carpi y M. Ortells Ramos, vol. 2, Valencia, 2008

FERNÁNDEZ-FÍGARES MORALES, M.J., "El principio de inmediación ante las declaraciones obtenidas mediante la captura y retransmisión audiovisual en el proceso penal”, Era Digital, Sociedad y Derecho, Coord., P. Arrabal Platero, Y. Doig Díaz, Dir., O. Fuentes Soriano, Ed. Tirant lo Blanch, Valencia, 2020

FONTESTAD PORTALÉS, L., "En busca de nuevas soluciones procesales y extraprocesales en el transporte marítimo de mercancías", Revista de Derecho del Transporte, núm., 26, 2020

GARCÍA COSTA, F.M., "Perfiles constitucionales de la justicia electrónica”, Modernización digital e innovación en la Administración de Justicia, Coord. M.F. Gómez Manresa y M. - Fernández Salmerón, Ed. Thomson Reuters Aranzadi, Cizur Menor, 2019.

GIMENO SENDRA, V., Fundamentos del Derecho Procesal, Ed. Cívitas, Madrid, 1981

HERRERA ABIÁN, R., La inmediación como garantía procesal, Ed. Comares, Granada, 2006 
KATSH, E., RIFKIN, J, GAITENBY, A., "E-Commerce, E-Disputes, and E-Dispute resolution: in the shadow of "eBay Law", Ohio State Journal on Dispute Resolution, vol. 15:3, 2000

KAUFMANN-KOHLER, G., y Schultz, T., Online Dispute Resolution: Challenges for Contemporary Justice, Kluwer Law International, 2004

LARSON, D.A., "Artificial Intelligence: Robots, Avatars, and the Demise of the Human Mediator", Ohio State Journal on Dispute Resolution, núm., 1, 2010

LETELIER LOYOLA, E., "Oralidad, inmediación y la determinación de las verdades en el proceso penal", Estudios actuales en Derecho y Ciencia Política, Coord. A. Carrizo González-Castell, Ed. Andavira, Santiago de Compostela, 2011

LÓPEZ RUIZ, F., "Notas entorno al principio de inmediación en el proceso penal. Una aproximación epistemológica”, Revista General de Derecho Procesal, núm., 40, 2016

MAGRO SERVET, V., "Hacia el uso habitual de la videoconferencia en las vistas judiciales. Aprovechando las enseñanzas del Coronavirus. De la excepción a la regla general del art. 19 RD 16/2020, de 28 de abril”, Diario La Ley, núm., 9639, 2020

MARTÍN DIZ, F., "Inteligencia artificial y proceso: garantías frente a eficiencia en el entorno de los derechos procesales fundamentales", Justicia: ¿garantías versus eficiencia?, Bellido Penadés. R., (dir), 2019

MARTÍN DIZ, F., Inteligencia artificial y medios extrajudiciales de resolución de litigios online (ODR): evolución de futuro en tiempos de pandemia global (COVID-19), Revista La Ley. Mediación y Arbitraje, núm. 2, 2020

MARTÍNEZ DE SANTOS, A., “Del juzgado y la sede física al proceso en línea”, Diario La Ley, núm., 9700, 2020

MATHEUS LÓPEZ, C., "Tecnología y arbitraje internacional en tiempos del coronavirus", CIAR Global (accesible en el vínculo: https://ciarglobal.com/tecnologia-y-arbitrajeinternacional-en-tiempos-del-coronavirus/ )

MÉNDEZ ZAMORA, E., "Panorama actual y futuro de la inteligencia artificial en el arbitraje internacional: implementaciones, obstáculos y consideraciones jurídicas”, Revista Costarricense de Derecho Internacional, núm., 1, 2018

MIRÓ LLINARES, F. "Inteligencia Artificial y Justicia Penal: más allá de los resultados lesivos causados por robots". Revista de Derecho Penal y Criminología, 3(20), 2018

MONTESINOS GARCÍA, A., La videoconferencia como instrumento probatorio en el proceso penal, Ed. Marcial Pons, Madrid, 2009 
NIETO GARCÍA, A.J., "El principio de inmediación, el lenguaje no verbal y gestual y las microexpresiones faciales”, Diario La Ley, núm., 9491, 2019

NIEVA FENOLL, J., "Oralidad e inmediación en la prueba: luces y sombras", Civil Procedure Review, vol.1, n. ${ }^{\circ}$ 2, 2010

NIEVA FENOLL, J., Inteligencia artificial y proceso judicial, Marcial Pons, Madrid, 2018

ORTELLS RAMOS, M., Introducción al Derecho Procesal, VV.AA., Tirant lo Blanch, $10^{\mathrm{a}}$ ed., Valencia, 2020

PAISLEY, K., Y SUSSMAN, E., “Artificial Intelligence Challenges and Opportunities for International Arbitration”, NYSBA NY Dispute Resolution Lawyer, núm., 1, 2018

ROGERS, C.A., "Arbitrator Intelligence: From Intuition to Data in Arbitrator Appointments", New York Dispute Resolution Lawyer. Vol. 11, núm., 2, 2018

RULE, C., HARPREET SINGH, H., “ODR and Online Reputation Systems - Maintaining Trust and Accuracy Through Effective Redress". Online Dispute Resolution: Theory \& Practice. A teatrise on technology and dispute resolution, Coord., M.S. Abdel Wahab, E. Katsh., D. Rainey, Eleven, 2011

SAGÜILLO TEJERINA, E., "El principio de inmediación y las nuevas tecnologías en el juicio penal", La Justicia digital en España y la Unión Europea, Coord. P., Arrabal Platero, P. García Molina, J. Conde Fuentes, Dir., G. Serrano Hoyo, Ed. Atelier, Barcelona, 2019

SCHWAB, K., La cuarta revolución industrial, Editorial Debate, 2016

SIM, C., "Will Artificial Intelligence Take Over Arbitration?", Asian International Arbitration Journal, núm., 1, 2018

SOLETO MUÑOZ, H., “Avances, tecnología y ADR en el sistema de justicia. La necesaria revolución de los sistemas de resolución de conflictos", La Justicia digital en España y la Unión Europea, J. Conde Fuentes y G. Serrano Hoyo (dirs.), Ed. Atelier, Barcelona, 2019

SURDEN, H., “Artificial intelligence and Law: an overview”, Georgia State University Law Review, vol., 35, núm., 4, 2019

TAVOLARI OLIVEROS, R., "La videoconferencia como mecanismo de comparecencia y la garantía del debido proceso" Revista Uruguaya de Derecho Procesal, núm., 1, 2006. 